Research Article

\title{
Numerical and Experimental Analyses of the Effect of Heat Treatments on the Phase Stability of Inconel 792
}

\author{
Maria M. Cueto-Rodriguez, ${ }^{1}$ Erika O. Avila-Davila $\mathbb{D}^{1},{ }^{1}$ Victor M. Lopez-Hirata $\mathbb{D},{ }^{2}$ \\ Maribel L. Saucedo-Muñoz, ${ }^{2}$ Luis M. Palacios-Pineda $\left(\mathbb{D},{ }^{1}\right.$ Luis G. Trapaga-Martinez, ${ }^{3}$ \\ and Juan M. Alvarado-Orozco ${ }^{4}$ \\ ${ }^{1}$ Tecnológico Nacional de México/Instituto Tecnológico de Pachuca (DEPI), Pachuca de Soto, Hgo. 42080, Mexico \\ ${ }^{2}$ Instituto Politécnico Nacional (ESIQIE), UPALM, Ciudad de México 07300, Mexico \\ ${ }^{3}$ CIATEQ-Posgrado en Manufactura Avanzada, Querétaro, Qro. 76150, Mexico \\ ${ }^{4}$ Centro de Ingeniería y Desarrollo Industrial (CIDESI), Querétaro, Qro. 76130, Mexico
}

Correspondence should be addressed to Erika O. Avila-Davila; osirisavila77@yahoo.com.mx

Received 1 September 2018; Accepted 15 November 2018; Published 9 December 2018

Academic Editor: Amelia Almeida

Copyright (C) 2018 Maria M. Cueto-Rodriguez et al. This is an open access article distributed under the Creative Commons Attribution License, which permits unrestricted use, distribution, and reproduction in any medium, provided the original work is properly cited.

\begin{abstract}
A study about the precipitation and phase stability was carried out in an IN-792 superalloy used as a blade in a gas turbine. Microstructure analysis was conducted experimentally on three different cross sections of the blade designated as high temperature (HT), medium temperature (MT), and low temperature (LT). To identify the HT, MT, and LT sections, a numerical thermal analysis was performed using ANSYS software. To obtain the distribution gradient of temperature in the blade, the real conditions of operation in steady state of the gas turbine were considered. A numerical study about the occurrence of phases in the IN-792 superalloy was carried out with Thermo-Calc and TC-PRISMA software. The analysis of the as-cast IN-792 superalloy with Scheil-Gulliver equations permitted to explain the phase formation during the solidification process. The calculated timetemperature-precipitation (TTP) diagram explains consistently the precipitation process observed after two different heat treatment conditions applied experimentally and numerically to regenerate the original microstructure of the IN-792 superalloy. The experimental results were consistent with the calculated isoplethic and TTP diagrams. In terms of accuracy, the further development of the Thermo-Calc databases for thermodynamic calculations in superalloys is evident. It was possible to calculate precipitation temperatures and the local evolution of precipitated particles for two different heat treatment conditions.
\end{abstract}

\section{Introduction}

The Ni-based superalloys have excellent mechanical properties under high-load bearing at temperatures up to approximately $85 \%$ of their incipient melting point, as well as, good environmental resistance and metallurgical stability under service conditions from about $813 \mathrm{~K}\left(540^{\circ} \mathrm{C}\right)$ and, in some cases, up to $1473 \mathrm{~K}\left(1200^{\circ} \mathrm{C}\right)$ [1]. These superalloys have been used since the early 1940s to manufacture diverse structural components of aerospace and land-based gas turbine engines exposed to the highest temperatures during the operation stages (e.g., combustor, turbine arrangements, and in the final high pressure of the compressor) [2].
The current performance of gas turbine engines is the result of continuous improvements in different areas of engineering, including alloy design, casting technology, and coating methods [3-5]. Critical rotary and stationary components in current gas turbine engines are mainly manufactured by directional solidification via columnarcrystal-structure or single-crystal technology in order to reduce or remove the grain boundaries, introduce a preferred grain orientation, and hence, improve its mechanical properties [2]. The remarkable mechanical properties of Ni-based superalloys are attributable to their precise chemical balance that promotes a coherent precipitation of the intermetallic compounds, $\gamma^{\prime}\left(\mathrm{L}_{2}-\mathrm{Ni} 3 \mathrm{Al}\right)$ and/or 
$\gamma^{\prime \prime}\left(\mathrm{D0}_{22}-\mathrm{Ni}_{3} \mathrm{Nb}\right)$, in a matrix phase, $\gamma(\mathrm{A} 1-\mathrm{Ni})$. The precipitates of $\gamma^{\prime}$ are usually aligned along the elastically softest crystallographic $<100\rangle$ direction [2]. The mechanical strength of $\gamma^{\prime}$ reinforced Ni-based superalloys is maintained at high temperatures due to $\gamma^{\prime}$ coarsening resistance. This characteristic is favored by a low value of lattice misfit between the $\gamma$ and $\gamma^{\prime}$ phases, which affects the interfacial energy between them [6].

The precipitation hardening of as-cast superalloys is generally carried out by a controlled heat treatment which may consist of a homogenization period followed by several aging steps. This treatment causes commonly a bimodal size distribution of $\gamma^{\prime}$ precipitates $[2,7,8]$. Additionally, it is known that superalloys are a good example of the more complex metallurgical systems due to the large number of alloying elements that compose them and promote the formation of other phases during its heat treatment and/or in-service operation. This fact makes difficult to determine what phases are stable after a heat treatment or during the component operation. For example, a study of the thermodynamic equilibrium for an IN-792 superalloy, using Thermo-Calc version $\mathrm{S}$, showed the occurrence of $\gamma, \gamma^{\prime}$, $\mathrm{M}_{23} \mathrm{C}_{6}$ and $\sigma$ phases in the calculated isothermal diagram at $973 \mathrm{~K}\left(700^{\circ} \mathrm{C}\right)$ [9]. It was concluded that even though the calculations predicted both $\sigma$-phase and $\mathrm{M}_{23} \mathrm{C}_{6}$ carbides to be thermodynamically stable, the experimental results showed occurrence of $\mathrm{M}_{23} \mathrm{C}_{6}$ carbides without $\sigma$-phase [9]. It is important to mention that an essential difference between this study and the analysis in [9] is the Thermo-Calc database used for the thermodynamic calculations. Another difference is that the blade in this study has an improved engineering design and cooling channels $[2,3]$. This technological improvement increases the efficiency of the gas turbine and suggests that the blade operates under severe conditions of service, such as higher temperature [2]. Thus, the microstructural stability, which is related to the mechanical integrity of this component, acquires major technological and scientific interest. So, several experimental and theoretical efforts have been made to predict or estimate the phase evolution of superalloys under different aging conditions $[7,10-12]$. Other phases like the topologically packed phases (TCP) can frequently appear into the microstructure of Ni-based superalloys. The TCP phases contain excessive amounts of $\mathrm{Cr}, \mathrm{W}$, and Mo that promote the precipitation of intermetallic phases enriched with these elements [2]. These phases have a high atomic density and some degree of nonmetallic behavior with directional bonding, as well as complex crystalline structures. The TCP phases have the general chemical formula $\mathrm{A}_{x} \mathrm{~B}_{y}$, where $\mathrm{A}$ and $\mathrm{B}$ are transition metals. Some examples are the $\mu, \sigma, R$, and $P$ phases [2]. Thus, TCP phases are incoherent with the $\gamma$ matrix phase and therefore do not contribute significantly to the mechanical strength. Additionally, different carbides and borides may be formed during processing or service, and their type and structure (i.e., $M C, M_{6} C, M_{23} C_{6}, M_{7} C_{3}$, and $M_{3} B$ ) depend on the alloy composition and thermal history to which Ni-based superalloy was subjected [13]. The continuous formation of these phases is recommended to be avoided on the grain boundaries, although there is little information about it. Their presence in these regions is due to an inadequate choice of processing temperatures or heat treatment of the superalloy to obtain the best mechanical properties $[2,11,14,15]$. Then, the study of phases formation and their evolution is an important issue to be investigated for Ni-based superalloys. Recently, the computational thermodynamic, based on CALPHAD methodology, has emerged as an important alternative to analyze the phase stability and growth kinetics of precipitation in alloys. For instance, Thermo-Calc and TCPRISMA have been employed to analyze the phase transformations of alloys $[9,16-18]$. Thus, the purpose of present work is to study experimentally and numerically the precipitation, coarsening process, and stability of the formed phases for an IN-792 superalloy. The analyzed blade was used in the first stage of a land-based gas turbine, and after, heat treatments were applied to regenerate the precipitation process in order to study their effect on the superalloy hardness.

\section{Experimental Procedure}

The IN-792 superalloy was obtained from a gas turbine firststage blade, with a length of about $103 \mathrm{~mm}$ over the blade root, after 12,000 h of service. Chemical composition of the superalloy was determined by an atomic absorption spectrometer, Varian Spectr AA-220 FS. Microstructural characterization was performed at three transversal sections along the blade length, designated as high temperature $\mathrm{HT} \sim 1211 \mathrm{~K} \quad\left(938^{\circ} \mathrm{C}\right)$, medium temperature $\mathrm{MT} \sim 1147 \mathrm{~K}$ $\left(874^{\circ} \mathrm{C}\right)$, and low temperature $\mathrm{LT} \sim 1091 \mathrm{~K}\left(818^{\circ} \mathrm{C}\right)$ located at 50,90 , and $10 \mathrm{~mm}$ from the blade root, respectively. Specimens were prepared metallographically and then etched with $\mathrm{FeCl}_{3}: 5 \mathrm{~g}, \mathrm{HCl}: 2 \mathrm{~mL}$, and ethanol: $100 \mathrm{~mL}$ [19] to be observed by optical microscopy (OM), with an Axio Observer D1m (Carl Zeiss) and by scanning electron microscopy (SEM), with a Jeol Thermo Scientific JSM-6300 at $20 \mathrm{kV}$, equipped with EDX analysis. Phase characterization was pursued by X-ray diffraction (XRD) with copper $\mathrm{K}_{\alpha}$ radiation, with a Bruker D8 FOCUS X-ray diffractometer. Quantitative metallography of microstructure was conducted by image analysis using ImageJ software. Vickers microhardness was determined using a load of $50 \mathrm{~g}$ for $12 \mathrm{~s}$.

Reheat treatments of IN-792 superalloy specimens were carried out only in the blade root considering, from the results of design and structural analysis of gas turbine blades, that this section is exposed to the lowest values of total deformation [20-22]. The conditions for heat treatments were as follows [23]: first, heating at $1393 \mathrm{~K}\left(1120^{\circ} \mathrm{C}\right)$ for $4 \mathrm{~h}$ with an electric tubular furnace, then air cooling. Next heating at $1393 \mathrm{~K}\left(1120^{\circ} \mathrm{C}\right)$ for $4 \mathrm{~h}$ followed by rapid air cooling until $1353 \mathrm{~K}\left(1080^{\circ} \mathrm{C}\right)$ and then aging at this temperature for $4 \mathrm{~h}$ and final aging at $1118 \mathrm{~K}\left(845^{\circ} \mathrm{C}\right)$ for $24 \mathrm{~h}$ followed by air cooling. Heat-treated specimens were previously encapsulated in quartz tubes, first evacuated to $10^{-2} \mathrm{~Pa}$ and then filled with pure Ar gas. These specimens were also characterized by OM, SEM, XRD, and Vickers microhardness test. 


\section{Numerical Procedure}

3.1. Fluid Flow and Thermal Analysis. First, a computational fluid dynamics (CFD) calculation was carried out to obtain the temperature produced by the gas flow on the blade surface [24]. Then, these results were used as boundary conditions in a conduction heat transfer analysis to determine the temperature distribution inside of the blade. All computations were performed at steady state condition using the finite volume method and finite element method (FEM) implemented in ANSYS software. The CFD domain was considered between the end of the first stage nozzle and the beginning of the second stage nozzle, with the following boundary conditions: inlet and outlet static pressure of 1.43 MPa and 1.02 MPa, respectively; inlet and outlet flow temperature of $1316 \mathrm{~K}\left(1043^{\circ} \mathrm{C}\right)$ and $1135 \mathrm{~K}\left(862^{\circ} \mathrm{C}\right)$, respectively; and, a mass flow of $2.11 \mathrm{~kg} / \mathrm{s}$. It is important to mention that the cooling flow was also taken into account and the cooling flow inlet velocity was $256.4 \mathrm{~m} / \mathrm{s}$ at $612 \mathrm{~K}$ $\left(339^{\circ} \mathrm{C}\right)$. The high pressure turbine was rotating at an angular speed of $8405 \mathrm{rpm}$. The discretized CFD domain contained 287638 vertexes and 281100 cells with $7.82 \times 10^{-4} \mathrm{~m}$ of minimum edge length. Additionally, the heat transfer domain by conduction was discretized with 32777 nonlinear elements $[24,25]$. The condition of ceramic coating on the blade was not considered in this study. The attention was focused on the temperature distribution in three cross sections located at different blade heights (bh), measured from its platform. The first one was located near the platform $(\mathrm{bh}=10 \mathrm{~mm})$, the second one was situated at midspan $(\mathrm{bh}=$ $50 \mathrm{~mm}$ ), and the third one was positioned near the blade tip $(\mathrm{bh}=90 \mathrm{~mm})$.

3.2. Thermo-Calc Analysis. Thermo-Calc, TC software $2016^{\mathrm{a}}$ version 8.0, [26] was used to determine the equilibrium and nonequilibrium phases for the IN-792 superalloy. The single point calculation, phase diagram, and property diagram modules were utilized to analyze the equilibrium phases based on the chemical composition of the alloy, temperature, and thermodynamic database TCNi8: Ni-Alloys v8.0 and MOBNi: Ni-Alloys v8.0. In contrast, the Scheil module was employed to determine the nonequilibrium phases expected for as-cast IN-792 superalloy. This module is based on the solution of Scheil-Gulliver equation [27]. The analysis of growth kinetic for precipitation was conducted using TCPRISMA during aging of the IN-792 superalloy. The TCPRISMA precipitation module [28] is based on Langer and Schwartz (LS) theory and uses the Kampmann and Wagner (KW) numerical method [29] to simulate the concomitant nucleation, growth, and coarsening of precipitates for multicomponent and multiphase alloy systems. The solution of equations for the LS theory enables to calculate the time evolution of the particle size distribution, mean radius, and the number density. The simplified growth model was used in precipitation simulations. The initial chemical composition for the precipitation analysis was assumed to be that corresponding to the maximum microsegregation of the $\gamma$ phase dendritic structure calculated with TC using the
Scheil-Gulliver equation. The concentrations of most of the alloying elements were slightly lower than their corresponding concentrations in the superalloy. The kinetic and thermodynamic data were acquired from the TC databases for Ni-based alloys [30]. The molar volumes of the matrix and precipitated phases for the superalloy were also calculated from the TC databases. The interface energy between the $\gamma^{\prime}, \mathrm{M}_{23} \mathrm{C}_{6}, \mu$ precipitates, and $\gamma$ matrix phase were calculated by TC-PRISMA. Homogeneous nucleation was assumed for the precipitation simulation in the austenite matrix, which is referred as "bulk nucleation" in TCPRISMA.

\section{Results and Discussion}

4.1. Thermal Analysis. Figures 1(a)-1(c) show the temperature distribution in the blade, obtained from FEM calculations. Frequently, these studies only show the temperature distribution on the blade surface $[5,22,31,32]$. In this case, it was taken into account the cross section to analyze in order to obtain a good reference of the service temperature. The microstructural characterization was performed in specific locations, indicated with black square points, for high temperature $(\mathrm{HT})$, medium temperature $(\mathrm{MT})$, and low temperature (LT). The section with higher gradient of temperature corresponds to the section near the blade root where temperatures from $1168 \mathrm{~K}\left(895^{\circ} \mathrm{C}\right)$ to $994 \mathrm{~K}\left(721^{\circ} \mathrm{C}\right)$ were obtained (Figure 1(c)). However, it is clear that the highest temperature in this section is located in a small area near the trailing edge. Thus, the highest gradient of temperature in the blade can be considered that of the section at midspan (Figure 1(b)), where a substantial area of the section is exposed to a major gradient of temperature, from $1211 \mathrm{~K}\left(938^{\circ} \mathrm{C}\right)$ to $1053 \mathrm{~K}\left(780^{\circ} \mathrm{C}\right)$. It is important to mention that the operating parameters and material properties used in FEM simulations correspond to actual conditions of the gas turbine [25]. The substrate temperatures obtained by this computation are close to those obtained in similar works $[5,22,32]$.

4.2. Thermodynamic Analysis of IN-792 Superalloy. The Thermo-Calc-calculated isoplethic phase diagram, plot of temperature (K) versus $\mathrm{Al}$ composition (wt.\%), is shown in Figure 2 for the IN-792 superalloy. The real chemical composition is shown in Table 1.

The current $\mathrm{Al}$ content is about $3.2 \mathrm{wt} . \%$, indicated in Figure 2 with a dotted line. If a very slow cooling process is analyzed for an IN-792 alloy with this aluminum content, from the liquid state, at $1643 \mathrm{~K}\left(1370^{\circ} \mathrm{C}\right)$ approximately, the first phases to be formed are carbides of the MC type and the $\gamma$ matrix phase. It is well known that the Ni-based superalloys are characterized by having a hardening $\gamma^{\prime}$ phase [2], which is also observed in the diagram over $1373 \mathrm{~K}\left(1100^{\circ} \mathrm{C}\right)$. As the temperature decreases other phases, such as borides, carbides of $\mathrm{M}_{23} \mathrm{C}_{6}$ type, TCP phases, and $\mathrm{Ni}_{3}$ Ti phase, are formed. In addition, it is important to note that there is no a previous report about a pseudobinary phase diagram of the IN-792 superalloy determined by numerical simulation. All 


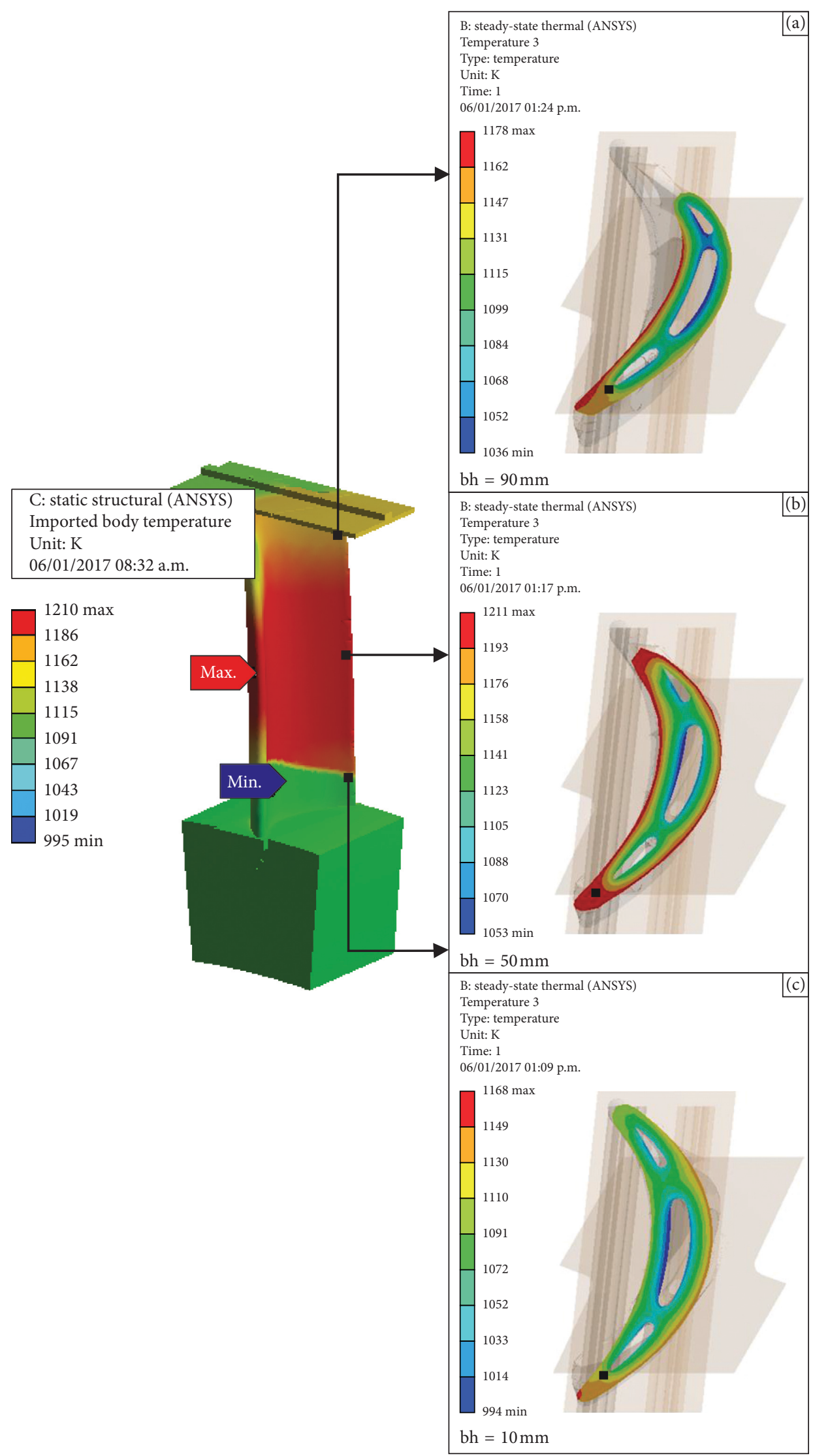

FIGURE 1: Calculated temperature distribution gradients of the blade for sections: (a) MT, (b) HT, and (c) LT. 


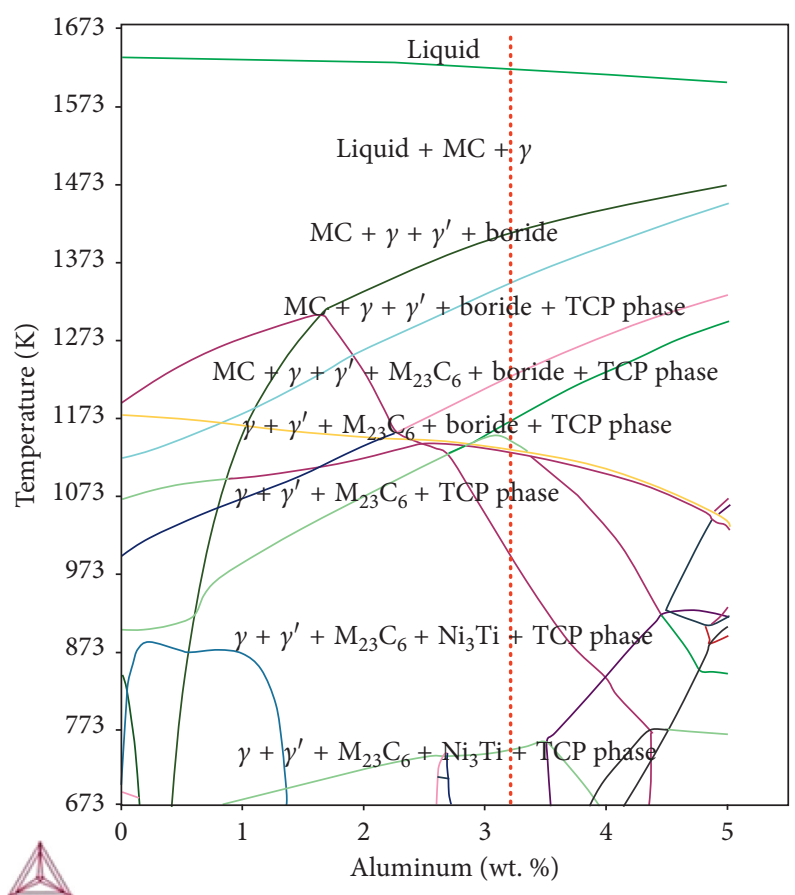

Figure 2: Isoplethic Ni-Al phase diagram of IN-792 superalloy.

TABLe 1: Real chemical composition (wt. \%) of IN-792 superalloy.

\begin{tabular}{lccccccccccccc}
\hline $\mathrm{Ni}$ & $\mathrm{Cr}$ & $\mathrm{Co}$ & $\mathrm{W}$ & $\mathrm{Al}$ & $\mathrm{Ti}$ & $\mathrm{Ta}$ & $\mathrm{Mo}$ & $\mathrm{Hf}$ & $\mathrm{Fe}$ & $\mathrm{C}$ & $\mathrm{Zr}$ & $\mathrm{V}$ & $\mathrm{Nb}$ \\
\hline Balance & 11.7 & 9.0 & 3.5 & 3.2 & 3.8 & 3.14 & 2.0 & 0.49 & 0.26 & 0.15 & 0.05 & 0.05 & 0.01 \\
\hline
\end{tabular}

phases shown in Figure 1, obtained by Thermo-Calc, are consistent with those reported in the literature for this type of Ni-based superalloys [2, 33]; however, their occurrence will depend on the real chemical composition of the superalloy.

4.3. Phase Analysis of As-Cast IN-792 Superalloy by ScheilGulliver Equation. Figure 3 shows the plot of temperature $(K)$ versus mol fraction of solid determined using the Thermo-Calc Scheil module. This diagram represents an approximation of the solidification in nonequilibrium state based on the Scheil-Gulliver model. This model assumes a solidification process with no diffusion in the solid phase, a perfect mixing in the liquid phase (infinitely rapid diffusion in the liquid phase), and local equilibrium at the liquid/solid interface. It shows the phases in as-cast state for the IN-792 superalloy. Here, it is clear that the first solids to be formed are carbides of the MC type and $\gamma$ matrix phase. According to the diagram, they start to be formed at $1623 \mathrm{~K}\left(1350^{\circ} \mathrm{C}\right)$, approximately. These results are similar to that obtained in [33] where temperatures of phase transformations were investigated in a cast polycrystal nickel alloy IN-792-5A experimentally, using the method of differential thermal analysis (DTA) under a cooling rate of $283 \mathrm{~K}\left(10^{\circ} \mathrm{C}\right) / \mathrm{min}$ [33]. The hardening phase, $\gamma^{\prime}-\mathrm{Ni}_{3} \mathrm{Al}$, and the $\eta-\mathrm{Ni}_{3} \mathrm{Ti}$ phase appear near $1473 \mathrm{~K}\left(1200^{\circ} \mathrm{C}\right)$. It is important to say that $\eta$ phase was suggested experimentally into the interval of temperatures of $\gamma^{\prime}$ precipitation [33]. Then, it was impossible

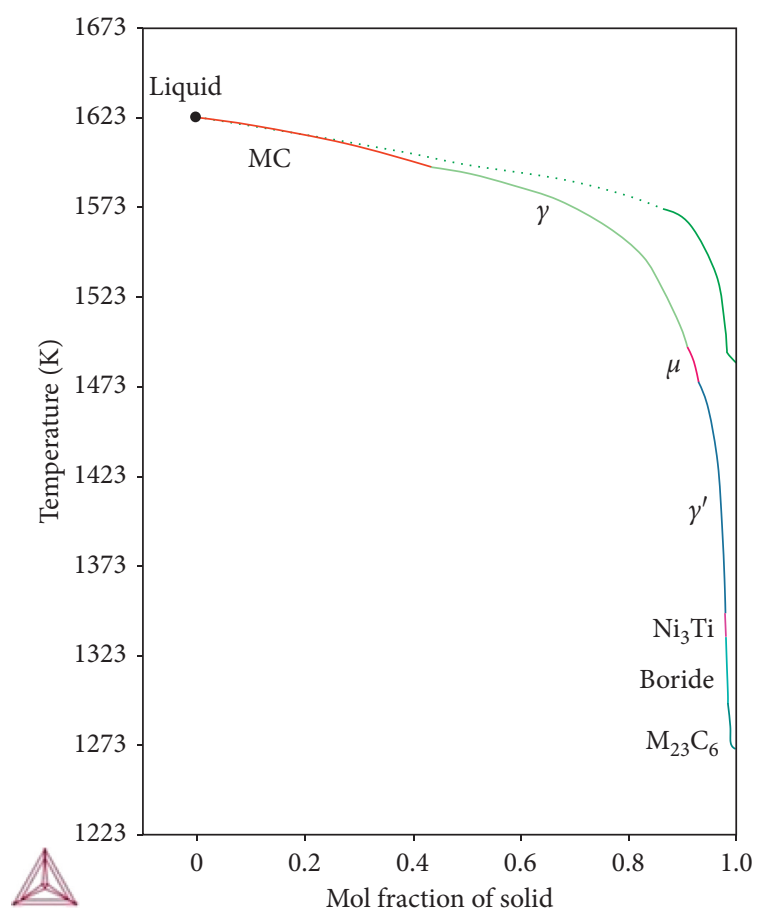

FIgURE 3: Temperature versus mol fraction of solid for the IN-792 superalloy.

to separate those thermal effects by DTA analysis and determine unequivocally temperatures of start and end of dissolution and precipitation of $\gamma^{\prime}$ and $\eta$ phases. In this case, 
Figure 3, it is possible to mention that $\gamma^{\prime}$ and $\eta$ phases start their precipitation at $1477 \mathrm{~K}\left(1204^{\circ} \mathrm{C}\right)$ and at $1347 \mathrm{~K}$ $\left(1074^{\circ} \mathrm{C}\right)$, respectively, and by comparison with [33], there is a difference of $279 \mathrm{~K}\left(6^{\circ} \mathrm{C}\right)$ and $278 \mathrm{~K}\left(5^{\circ} \mathrm{C}\right)$, respectively. The $\gamma$ and $\gamma^{\prime}$ phases have been reported to be present as a result of a eutectic reaction, also. The $\gamma^{\prime}$ phase formed on this way is designated as primary $\gamma^{\prime}$ phase $[2,4]$. The formation of $\mu$ phase in some Ni-based superalloys is unavoidable. It was shown that the $\mu$ phase can be formed in cast Ni-base superalloys when the amount of refractory elements, tungsten and molybdenum, is more than 3.5, and in these cases the $\mu$ phase will be the main TCP phase instead of the $\sigma$-phase [14]. So, the IN-792 superalloy of this study has a content of tungsten and molybdenum of about 5.5. The $\mu$ phase is based on the ideal stoichiometry $\mathrm{A}_{6} \mathrm{~B}_{7}$. Examples of this phase are $\mathrm{W}_{6} \mathrm{Co}_{7}$ and $\mathrm{Mo}_{6} \mathrm{Co}_{7}$ [2]. Also, it has been determined that a primary $\mu$ phase may form during solidification, and secondary $\mu$ phase can precipitate during aged heat treatment, or during service temperature in a range since $1073 \mathrm{~K}\left(800^{\circ} \mathrm{C}\right)$ to $1413 \mathrm{~K}\left(1140^{\circ} \mathrm{C}\right)$ in the $\mathrm{Ni}$ based superalloys [14]. At the end of the Scheil diagram, some borides and carbides, of the $\mathrm{M}_{23} \mathrm{C}_{6}$ type, are formed. These results are in agreement with those reported in the literature [2]. Besides, when the $\mathrm{C}$ content is in the range of 0.05 to 0.14 wt.\% in a superalloy, fine dispersed MC and $\mathrm{M}_{23} \mathrm{C}_{6}$ carbides could be formed [13]. This particular type of carbides strongly influences the mechanical properties of Ni-based superalloys; for example, it is possible to improve the strength of this material by a controlled amount of particles of these carbides that promote an apparent inhibition of grain boundary slip. However, a failure in the superalloy eventually could occur due to a fracture in the particle or by decohesion of the carbide/matrix interface. The $\mathrm{M}_{23} \mathrm{C}_{6}$ carbides can also cause premature failure, but this behavior can be avoided by mean of a controlled heat treatment in the superalloy [2].

The Thermo-Calc-calculated chemical composition of the as-cast $\gamma$ and $\gamma^{\prime}$ phases can be seen in Table 2. It is important to observe the proportion of the elements in the $\gamma$ matrix phase. As expected, nickel is the element contained in major proportion, about $65.51 \mathrm{wt} . \%$, and decreases to 60.02 wt.\%. This behavior is similar to the aluminum content that decreases from 3.64 to 2.59 wt.\%. Other elements are also present in $\gamma$ phase, but they increase in content, chromium from 12.11 to $12.58 \mathrm{wt}$ \% $\%$ and cobalt from 7.88 to $10.14 \mathrm{wt} . \%$. Besides, it is shown in Table 2, the nickel and aluminum content for $\gamma^{\prime}$ phase increase with respect to $\gamma$ matrix phase from 62.19 to 65.83 and from 2.83 to 3.74 wt.\%, respectively. The other elements of the $\gamma^{\prime}$ phase decrease in content for: chromium from 12.63 to 12.09 wt. $\%$ and cobalt from 9.98 to $8.5 \mathrm{wt} . \%$. It is clear that the compositional ranges are similar between the phases $\gamma$ and $\gamma^{\prime}$. On the other hand, it is evident a good agreement of the chemical composition values of the elements shown in Table 2 with these values obtained experimentally for the real chemical composition shown in Table 1. Also, in Table 2, it can be observed that some elements promote a preferred substitution for nickel, like cobalt, or some elements promote the formation of $\gamma^{\prime}$ phase, like aluminum and nickel. In both cases, the values of chemical composition for $\gamma$ and $\gamma^{\prime}$ coincide with that reported in literature [2].

An EDX analysis was carried out by SEM to the sample exposed at MT, near of leading edge and of suction side of the blade (Figure 4 ). The spectrums obtained are shown only for the points 3-4 y 7-8, for simplicity. It is clear that the values of chemical composition are very closer between $\gamma$ and $\gamma^{\prime}$ phases. However, it can be observed a larger content of nickel and aluminum for $\gamma^{\prime}$ phase than for $\gamma$ matrix phase. This behavior is observed in an element-imaging SEM analysis of the IN-792 superalloy for the same section of the blade, MT (Figure 5). So, the experimental results are in agreement with the Thermo-Calc-calculated chemical composition of the as-cast $\gamma$ and $\gamma^{\prime}$ phases.

4.4. Precipitation Analysis by TC-PRISMA. Figure 6 shows the time-temperature-precipitation (TTP) diagram for the IN-792 superalloy, determined by TC-PRISMA software. This diagram was calculated considering the chemical composition of as-cast $\gamma^{\prime}$ phase, shown in Table 2, and the following interfacial energy: 0.047, 0.17, 0.20, and $0.19 \mathrm{~J} / \mathrm{m}^{2}$ for the interfaces $\gamma^{\prime} / \gamma, \mu / \gamma, \mathrm{M}_{23} \mathrm{C}_{6} / \gamma$, and $\mathrm{Ni}_{3} \mathrm{Ti} / \gamma$, respectively. There is not a previous investigation about the TTP diagram for IN-792 superalloy, which is an important contribution because it is of great interest for the industry. The TTP diagram indicates that the isothermal aging at temperatures between approximately $1198 \mathrm{~K}\left(925^{\circ} \mathrm{C}\right)$ and $1323 \mathrm{~K}\left(1050^{\circ} \mathrm{C}\right)$ causes the following precipitation reaction:

$$
\gamma \longrightarrow \gamma+\gamma^{\prime}
$$

It is important to notice that the precipitation of $\gamma^{\prime}$ phase occurs very fast. This precipitate is known as secondary $\gamma^{\prime}$ precipitates.

In contrast, the precipitation sequence for aging at temperatures of about $873 \mathrm{~K}\left(600^{\circ} \mathrm{C}\right)$ and $1173 \mathrm{~K}\left(900^{\circ} \mathrm{C}\right)$ is as follows:

$$
\gamma \longrightarrow \gamma+\gamma^{\prime} \longrightarrow \gamma+\mu \longrightarrow \gamma+\mathrm{M}_{23} \mathrm{C}_{6} \longrightarrow \gamma+\mathrm{Ni}_{3} \mathrm{Ti}
$$

That is, $\gamma^{\prime}$ phase is the first precipitate to be formed and then $\mu, \mathrm{M}_{23} \mathrm{C}_{6}$, and $\mathrm{Ni}_{3} \mathrm{Ti}$ or $\eta$ phases appear successively as the aging time progresses.

It is important to mention that it was determined that $\eta$ phase is found at the grain boundaries in Ni-based alloys when the $\mathrm{Ti} / \mathrm{Al}$ ratios are higher than about 2.64 and after prolonged exposure at temperatures higher than $1073 \mathrm{~K}$ $\left(800^{\circ} \mathrm{C}\right)$ [34]. It is considered as deleterious phase because it usually poses negative impact on the mechanical properties of superalloys [34]. The Ti/Al ratio in this superalloy is of about 1.19. Thus, it would be not a surprise in this study not to observe this structure in the samples reheat treated to regenerate the precipitation process. But, the formation of $\eta$ phase in the blade used, after $12,000 \mathrm{~h}$ of service, could be possible.

The occurrence of $\mathrm{M}_{23} \mathrm{C}_{6}$ carbides were not experimentally detected in samples of IN-792-5A superalloy [33]. So, it would be not a surprise if this structure is not present in the samples re-heat-treated of this study due to the 
TABLE 2: Thermo-Calc-calculated chemical composition (wt. \%) of $\gamma$ and $\gamma^{\prime}$ phases for as-cast Ni-based superalloy.

\begin{tabular}{|c|c|c|c|c|c|c|c|c|c|c|}
\hline Phase & $\mathrm{Ni}$ & $\mathrm{Cr}$ & Co & $\mathrm{W}$ & $\mathrm{Al}$ & $\mathrm{Ti}$ & $\mathrm{Ta}$ & Mo & $\mathrm{C}$ & $\mathrm{Nb}$ \\
\hline$\gamma$ & $65.51-60.02$ & $12.11-12.56$ & $7.88-10.14$ & $2.89-4.70$ & $3.64-2.59$ & $2.06-4.72$ & $2.08-4.69$ & $2.05-2.88$ & $0.01-0.042$ & $0.005-0.0007$ \\
\hline$\gamma^{\prime}$ & $62.19-65.83$ & $12.63-12.09$ & $9.96-8.50$ & & $2.83-3.74$ & & & & & \\
\hline
\end{tabular}

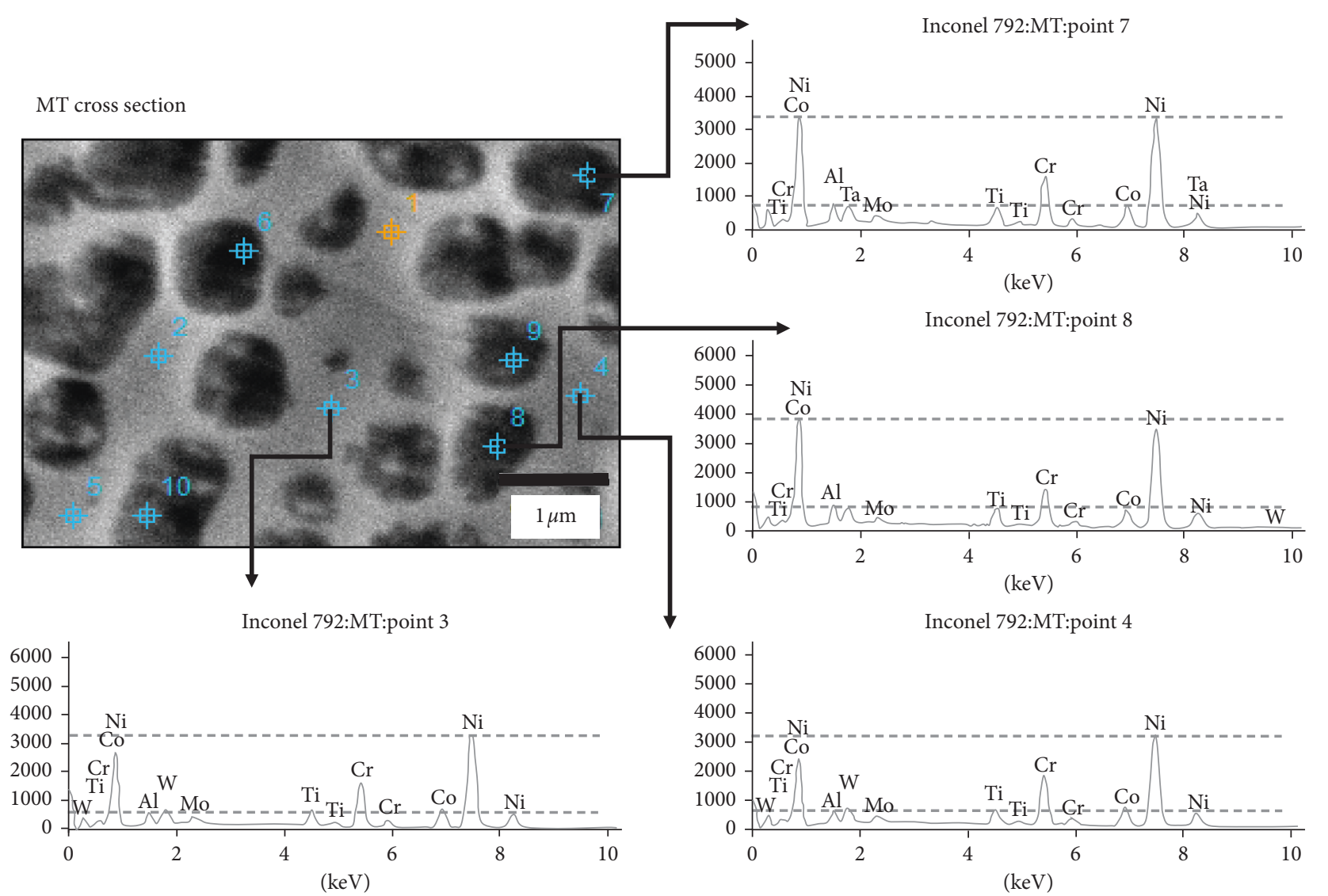

FIGURE 4: Analysis by EDX of the sample exposed at MT, near leading edge and suction side of the blade.

conditions of the heat treatments carried out. However, the formation of $\mathrm{M}_{23} \mathrm{C}_{6}$ carbides in the blade used, after 12,000 $\mathrm{h}$ of service, could be possible due to the decomposition of $\mathrm{MC}$ carbides that usually take place in Ni-based superalloys [2].

The TC-PRISMA simulation of heat treatment for the IN-792 superalloy was conducted considering the typical conditions: solution treatment at $1393 \mathrm{~K}\left(1120^{\circ} \mathrm{C}\right)$ for $4 \mathrm{~h}$ followed by rapid air cooling, then isothermal aging at $1353 \mathrm{~K}\left(1080^{\circ} \mathrm{C}\right)$ for $4 \mathrm{~h}$ followed by air cooling, and finally isothermal aging at $1118 \mathrm{~K}\left(845^{\circ} \mathrm{C}\right)$ for $24 \mathrm{~h}$ followed by air cooling. Thus, two different simulations were conducted to analyze the precipitation process during the heat treatment for IN-792 superalloy. The first treatment consisted of solution treating at $1393 \mathrm{~K}\left(1120^{\circ} \mathrm{C}\right)$ and subsequently isothermal aging at $1353 \mathrm{~K}\left(1080^{\circ} \mathrm{C}\right)$ for $4 \mathrm{~h}$. The second treatment involved the solution treating at $1393 \mathrm{~K}\left(1120^{\circ} \mathrm{C}\right)$ and subsequently a double isothermal aging until $1118 \mathrm{~K}$ $\left(845^{\circ} \mathrm{C}\right)$ for $4 \mathrm{~h}$. Figures $7(\mathrm{a})$ and 7 (b) show the plot of mean radius of precipitates $(\mathrm{nm})$ versus time (s) determined by TC-PRISMA software for the former and latter treatments, respectively. Figure 7 (a) shows that the precipitated corresponds to $\gamma^{\prime}$ phase. It is noted the presence of three stages: the first of them shows a continuous increase in radius with time up to about $165 \mathrm{~nm}$ after $100 \mathrm{~s}$ of aging. This corresponds to the nucleation and growth stage. Then, there is clearly a plateau, which indicates that the precipitate growth stops and thus, the coarsening stage is reached. This behavior has been observed in a previous study where it was identified that precipitate coarsening commences at the beginning of the second aging step [18]. In contrast, Figure 7(b) indicates that the precipitation of several phases, $\mathrm{M}_{23} \mathrm{C}_{6}, \gamma^{\prime}, \mu$, and $\mathrm{Ni}_{3} \mathrm{Ti}$, take place during aging at this condition. Furthermore, the radius of $\mathrm{M}_{23} \mathrm{C}_{6}$ precipitates is larger than that of the $\gamma^{\prime}$ phase. As expected, the radius of $\gamma^{\prime}$ precipitates is larger for aging at $1353 \mathrm{~K}\left(1080^{\circ} \mathrm{C}\right)$ than that at $1118 \mathrm{~K}$ $\left(845^{\circ} \mathrm{C}\right)$. This fact suggests that the size distribution of precipitates is a bimodal type for the complete treatment.

In addition, Figures 8(a) and 8(b) illustrate the plot of precipitate volume fraction as a function of time for the same conditions of Figures $7(\mathrm{a})$ and $7(\mathrm{~b})$. The volume fraction of the aging at $1353 \mathrm{~K}\left(1080^{\circ} \mathrm{C}\right)$ is much lower, about $18 \%$, than that of aging at $1118 \mathrm{~K}\left(845^{\circ} \mathrm{C}\right)$, approximately $42 \%$. These figures also show that the $\gamma^{\prime}$ phase is the first to be formed at both heat treatment conditions. These 

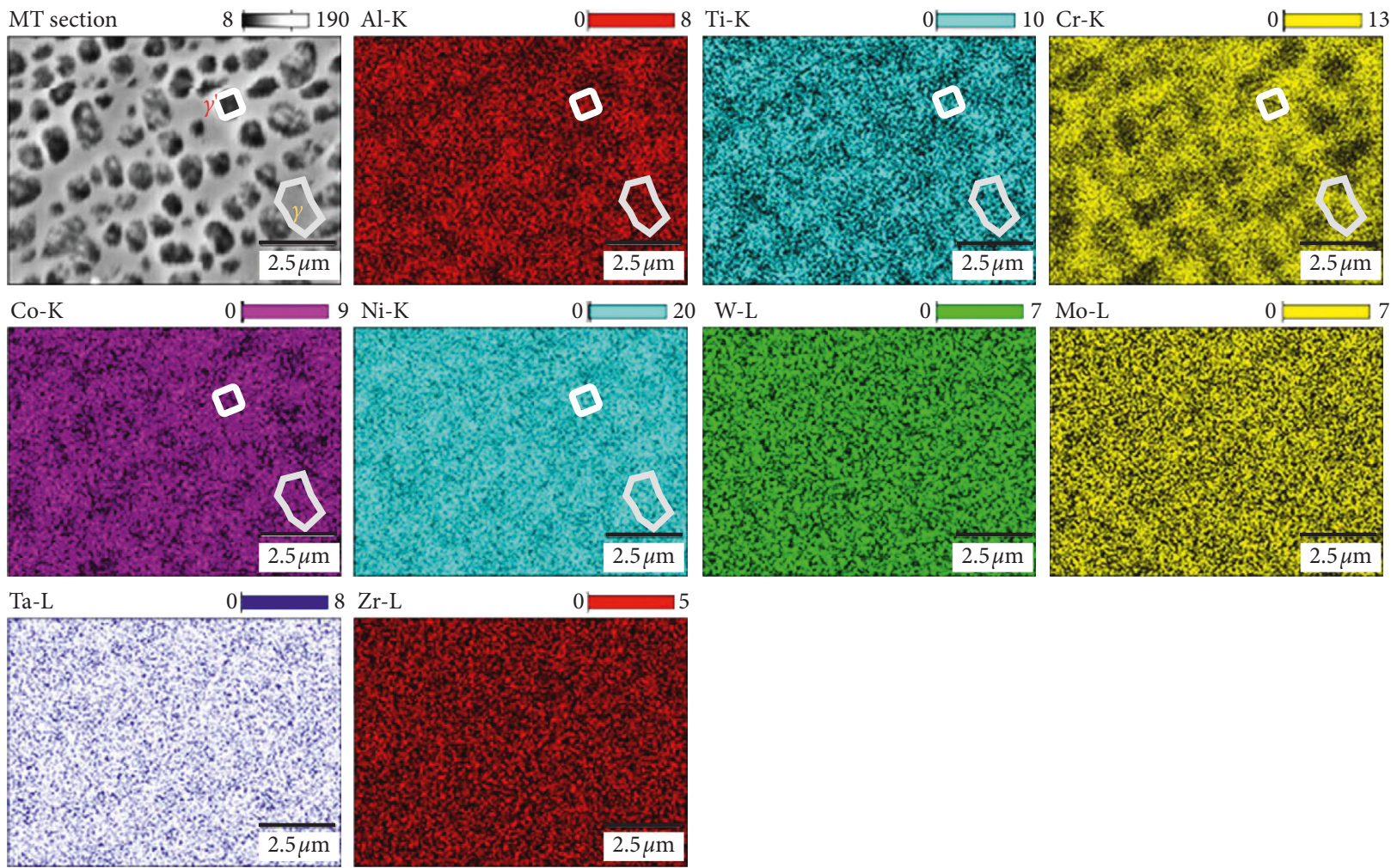

$\mathrm{Zr}-\mathrm{L}$

$0 \longdiv { \square }$

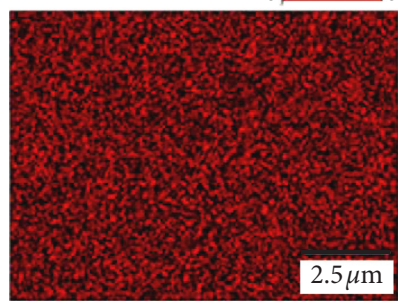

FIgURE 5: Element-imaging SEM analysis of IN-792 superalloy for MT section.

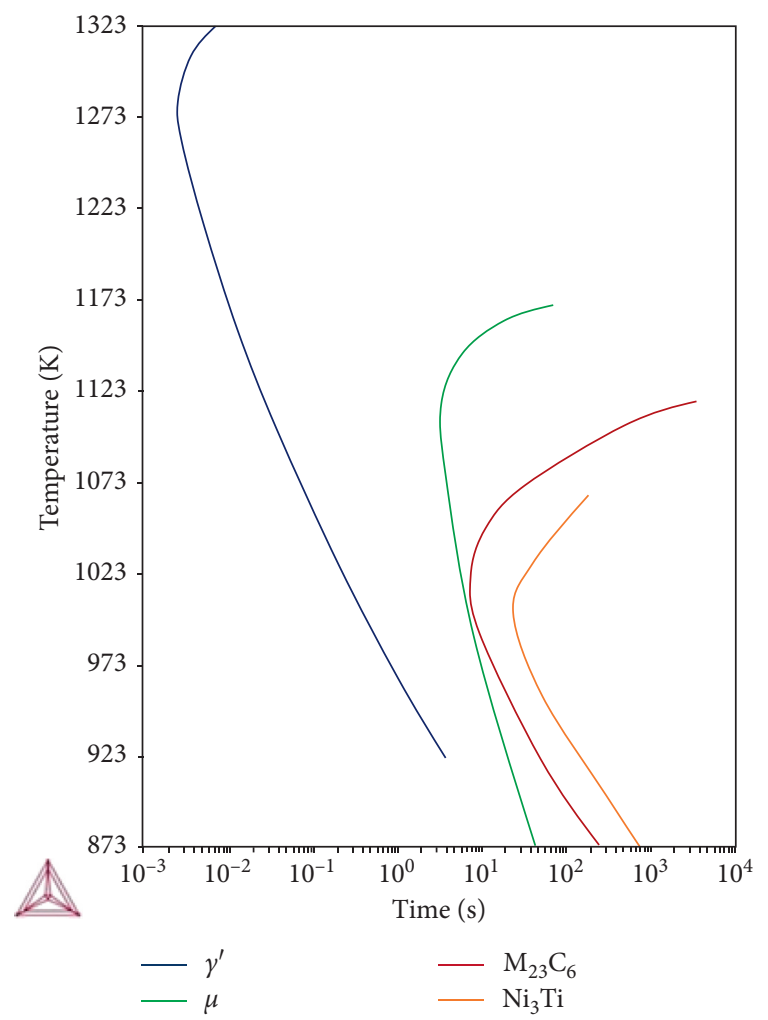

Figure 6: Time-temperature-precipitation diagram for IN-792 superalloy. results, Figures $7(\mathrm{a}), 7(\mathrm{~b}), 8(\mathrm{a})$, and $8(\mathrm{~b})$, are similar to those obtained in [35]. In that experimental study, it was determined the effect of the solution temperature on the microstructure of a Ni-based superalloy and they observed a primary $\gamma^{\prime}$ fraction of about $7.4 \%$ at solution temperature for subsolvus condition. No primary $\gamma^{\prime}$ fraction was identified for supersolvus condition. Also, it was determined the precipitation of secondary $\gamma^{\prime}$ particles from the matrix during quenching for different heat treatment conditions of aged [35]. The size of $\gamma^{\prime}$ precipitates increased as the cooling rate decreased, and different conditions of cooling in their aging treatments led to a bimodal precipitation of secondary $\gamma^{\prime}$ particles $[18,35]$. So, it is suggested that the results obtained in Figures $7(\mathrm{a})$ and 8(a) could be referred as a unimodal precipitation of $\gamma^{\prime}$ particles. Same behavior is suggested for the results obtained in Figures 7(b) and 8(b). It is important to mention that there is a previous study where the simulation of $\gamma^{\prime}$ precipitation kinetics was carried out in a commercial Ni-based superalloy with two simulation tools, TC-PRISMA and PanPrecipitation [18]. In that analysis, it was predicted that monomodal $\gamma^{\prime}$ size distributions were consistent with their experimental observations where the equilibrium volume fraction $\gamma^{\prime}$ obtained would virtually be established at the beginning of the second aging step [18]. Thus, this simulation results allow to know the local evolution of precipitated particles in components under different conditions of heat treatments. 


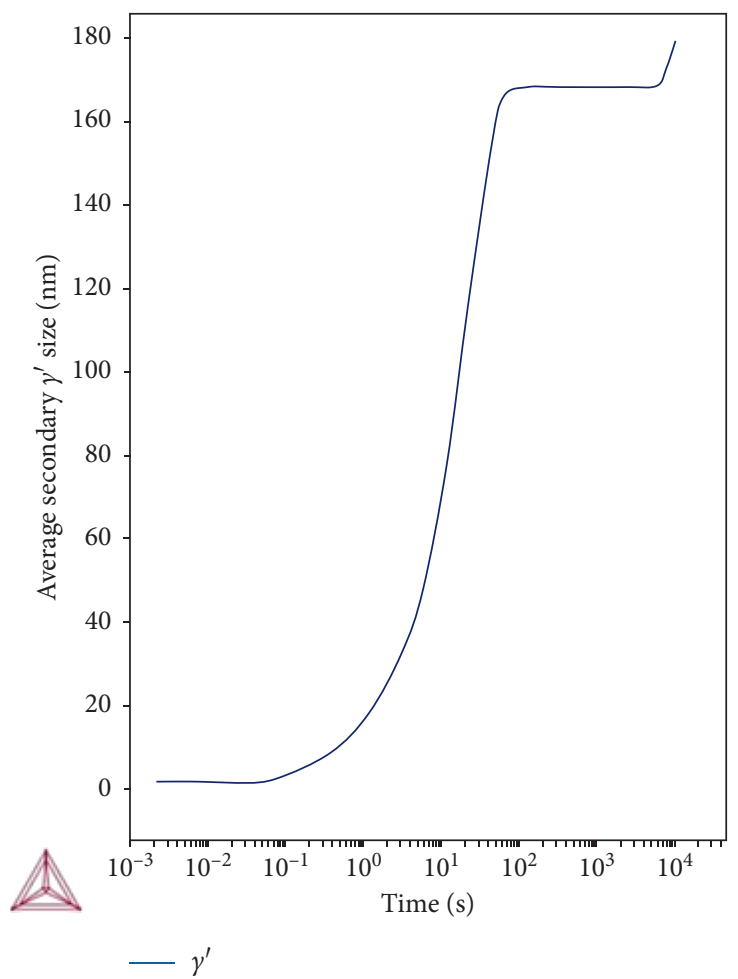

(a)

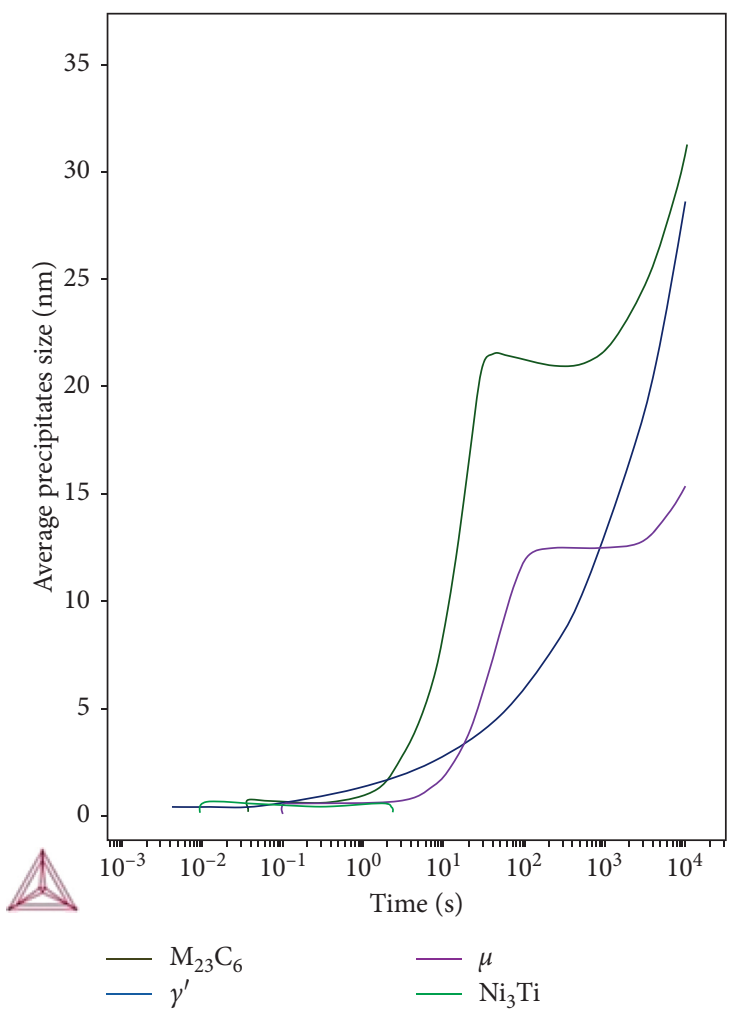

(b)

Figure 7: Mean radius of precipitates versus time for the conditions of heat treatment of (a) isothermal aging until $1353 \mathrm{~K}\left(1080^{\circ} \mathrm{C}\right)$ and $(\mathrm{b})$ double isothermal aging until $1118 \mathrm{~K}\left(845^{\circ} \mathrm{C}\right)$.

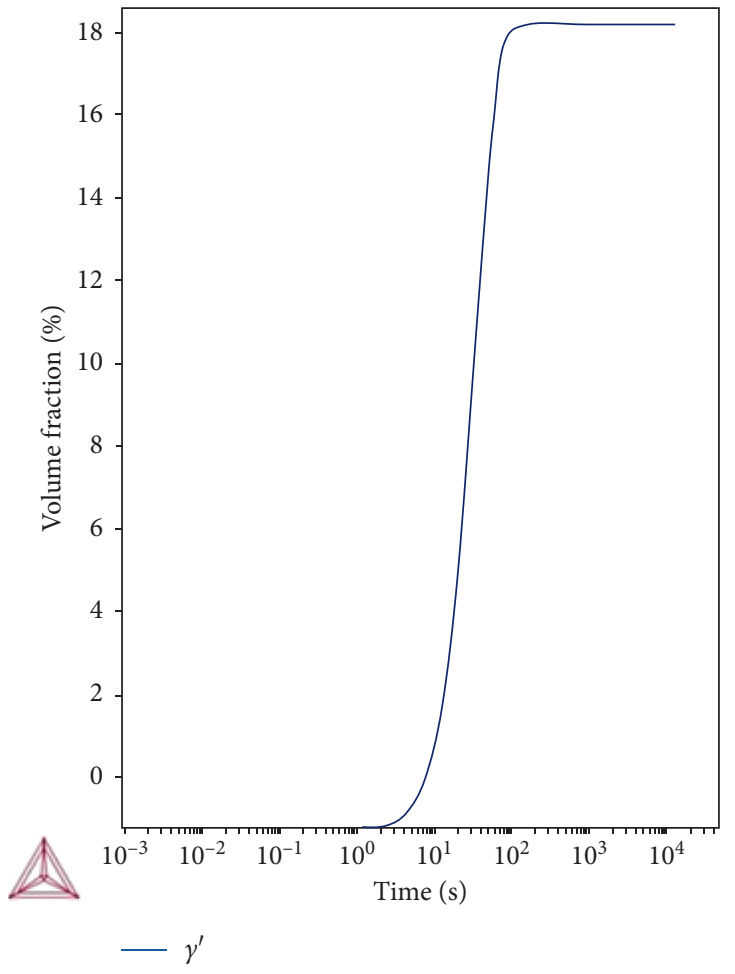

(a)

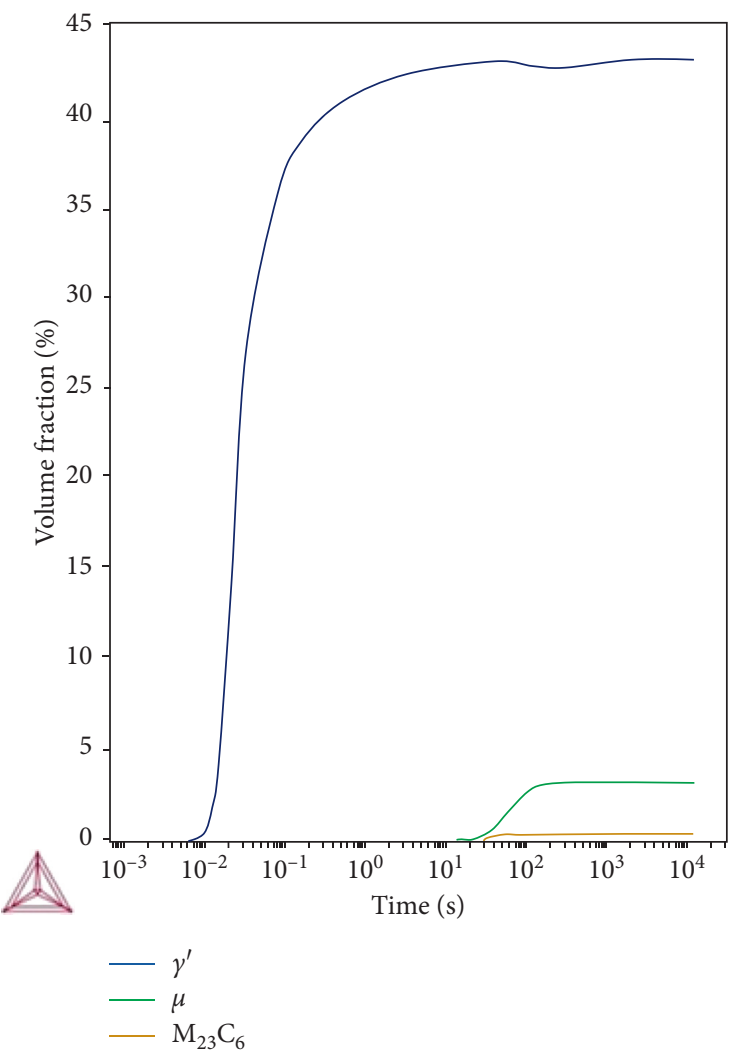

(b)

Figure 8: Volume fraction of precipitates versus time for the conditions of heat treatment of (a) isothermal aging until $1353 \mathrm{~K}\left(1080^{\circ} \mathrm{C}\right)$ and (b) double isothermal aging until $1118 \mathrm{~K}\left(845^{\circ} \mathrm{C}\right)$. 
4.5. Microstructural and Mechanical Characterization of InService Operation Blade for Power Plant Turbine. In this study, the macroscopic analysis of IN-792 showed that this superalloy was obtained by a directional solidification process (SD). The results of the microstructure revealed by SEM are shown in Figures 9(a)-9(c) for the three sections: MT: $1147 \mathrm{~K}\left(874^{\circ} \mathrm{C}\right)$; HT: $1211 \mathrm{~K}\left(938^{\circ} \mathrm{C}\right)$; and LT: $1091 \mathrm{~K}$ $\left(818^{\circ} \mathrm{C}\right)$, respectively. It can be observed the different formed phases: $\gamma$ matrix (light gray), $\gamma^{\prime}$ precipitate (dark gray), and carbides of the MC type (white). The MC carbides, with a size of approximately $10 \mu \mathrm{m}$, are clearly observed in Figures $9(\mathrm{a})-9(\mathrm{c})$. These are the first phase to be formed during the solidification, as shown in Figure 3. They are composed of $\mathrm{Ti}$ and $\mathrm{Ta}$, as indicated in Figure 10, which corresponds to the element-imaging SEM analysis of the IN792 superalloy, in addition to $\mathrm{M}_{23} \mathrm{C}_{6}$ carbides (black) near the MC carbides, due to the decomposition of $\mathrm{MC}$ carbides that usually take place in Ni-based superalloys, as previously mentioned. This may cause the release of carbon that reacts in several ways and leads to the formation of $\mathrm{M}_{23} \mathrm{C}_{6}$ according to the following reactions [2]:

$$
\mathrm{MC}+\gamma \longrightarrow \mathrm{M}_{23} \mathrm{C}_{6}+\gamma^{\prime} t
$$

$(\mathrm{Ti}, \mathrm{Mo}) \mathrm{C}+(\mathrm{Ni} ; \mathrm{Cr}, \mathrm{Al}, \mathrm{Ti}) \longrightarrow \mathrm{Cr}_{21} \mathrm{Mo}_{2} \mathrm{C}_{6}+\mathrm{Ni}_{3}(\mathrm{Al}, \mathrm{Ti})$

These reactions promote the precipitation of carbides mainly on grain boundaries and, in many cases, the $\gamma^{\prime}$ phase generated by reaction (3) covers the surface of MC carbides [2]. This is in agreement with the MC carbides observed in Figures 9(a)-9(c) which are covered by $\gamma^{\prime}$ phase.

In addition to, a different coarse microconstituent with an irregular plate shape was observed in Figure 9(c), indicated with black arrows. This constituent may correspond to a topologically packed phase (TCP). It is known that the TCP phases are formed in Ni-based superalloys that have high content of elements such as $\mathrm{Cr}, \mathrm{Mo}, \mathrm{W}$, or Re which promote precipitation of rich intermetallic phases in these elements [2]. The real chemical composition of IN-792 superalloy indicates a high $\mathrm{Cr}$ content, $11.7 \mathrm{wt} . \%$, Mo and $\mathrm{W}$, with 2.0 and $3.5 \mathrm{wt} . \%$, respectively. This may cause the formation of the $\mu$ phase according to Thermo-Calc and TCPRISMA results, previously presented. Also, it was shown in Figure $8(\mathrm{~b})$ a low value of volume fraction for this precipitate. Additionally, particles of the $\gamma^{\prime}$ phase can be accumulated and coarsened around the $\mu$ phase. Thus, the identification of $\mu$ phase is difficult by SEM [14].

The eutectic $\gamma$ and $\gamma^{\prime}$ lamellar constituent is noted in Figures 9(a)-9(c). This eutectic reaction was identified at $1504 \mathrm{~K}\left(1231^{\circ} \mathrm{C}\right)$ [33]. The aging process at temperatures between $1118 \mathrm{~K}\left(845^{\circ} \mathrm{C}\right)$ and $1353 \mathrm{~K}\left(1080^{\circ} \mathrm{C}\right)$ is expected to cause the precipitation of the $\gamma^{\prime}$ phase from the $\gamma$ phase of ascast superalloy. These precipitates have a cuboid morphology as can be observed in Figures 9(a)-9(c). They are also aligned on the softest crystallographic direction of the fcc $\gamma$ phase, $\langle 100\rangle$. The average radius of $\gamma^{\prime}$ particles, determined on different SEM micrographs, was HT: $338.5 \mathrm{~nm}$; MT: $320.4 \mathrm{~nm}$; and, LT: $328.5 \mathrm{~nm}$. It is evident that the highest service temperature promotes the largest size of $\gamma^{\prime}$ particles. However, the smallest radius of precipitates was not observed for LT section. This seems to be attributable to the occurrence of rafting of $\gamma^{\prime}$ precipitates in MT section due to the presence of highest value of total deformation in this section and to high mechanical stress during in-service operation of the blade.

The XRD pattern for superalloy, after in-service operation, is shown in Figure 11(a). Most of the diffraction peaks for $\gamma^{\prime}$ and $\gamma$ phases are overlapped because of the similar lattice parameter; however, the superlattice diffraction peaks of $\gamma^{\prime}$ phase are clearly detected at low $2 \theta$ angle. The elementimaging SEM analysis of Figure 10 revealed the presence of $\mathrm{M}_{23} \mathrm{C}_{6}$ carbides, mainly composed of $\mathrm{Cr}$ and $\mathrm{Mo}$, and it is confirmed in Figures 11(a) and 11(b). This fact is consistent with literature [2] where it is reported that $\mathrm{M}_{6} \mathrm{C}$ carbide is favored to be formed instead of $\mathrm{M}_{23} \mathrm{C}_{6}$ carbide for nickelbased superalloys where Mo and $\mathrm{W}$ content is in the range of 6-8 at. \%, which is different from 1.21 at. \% Mo and 1.11 at. \% $\mathrm{W}$ for the current alloy composition.

Figure 11(a) confirmed the presence of $\mathrm{Ni}_{3} \mathrm{Ti}$ or $\eta$ phase, predicted by Thermo-Calc and TC-PRISMA software. It was expected to take place due to the in-service operation conditions of the blade. The presence of $\eta$ phase identified in this investigation is similar to that of the results obtained in $[33,34]$. However, $\eta$ phase was not detected by SEM.

It is important to mention that $\mu$ particles were not identified in previous studies about precipitation kinetic of IN-792 superalloys $[9,33]$. This can be attributed to little differences of chemical composition and to the different bases of thermodynamics data used in this study.

The Vickers microhardness of the blade for each section, HT, MT, and LT, was determined to be about 478,434 and 453 VHN, respectively. This difference in hardness can be attributed to the $\gamma^{\prime}$ phase average size. Besides, the highest value hardness was observed to occur when a high volume fraction of $\mathrm{MC}$ and $\mathrm{M}_{23} \mathrm{C}_{6}$ carbides were present, distributed intra- and intergranularly in the $\gamma$ matrix phase.

4.6. Microstructural and Mechanical Characterization of the Reheat-Treated Blade. Figures 12(a)-12(f) show the SEM micrographs for the base of the blade with the following heat treatment conditions: heating at $1393 \mathrm{~K}\left(1120^{\circ} \mathrm{C}\right)$ for $4 \mathrm{~h}$ and subsequently air cooling (Figures 12(a)-12(c)), heating at $1393 \mathrm{~K}\left(1120^{\circ} \mathrm{C}\right)$ for $4 \mathrm{~h}$ followed by rapid air cooling until $1353 \mathrm{~K}\left(1080^{\circ} \mathrm{C}\right)$, and then aging at this temperature for $4 \mathrm{~h}$ and final aging at $1118 \mathrm{~K}\left(845^{\circ} \mathrm{C}\right)$ for $24 \mathrm{~h}$ followed by air cooling (Figures 12(d)-12(f)). The first heat treatment caused the partial dissolution of the $\gamma^{\prime}$ phase because of the decrease in its volume fraction. That is, the $\gamma^{\prime}$ particles were not observed well distributed on the $\gamma$ matrix, and its average radius decreased, approximately $312 \mathrm{~nm}$. Furthermore, the crystallographic alignment between the $\gamma$ and $\gamma^{\prime}$ phases is not clearly observed in Figures 12(a)-12(c). Additionally, the morphology of $\gamma^{\prime}$ precipitates is rounded instead of cuboidal. This result suggests that the $\gamma^{\prime}$ phase was not completely dissolved which is in agreement with the pseudobinary phase diagram of Figure 2 where no $\gamma$ single 


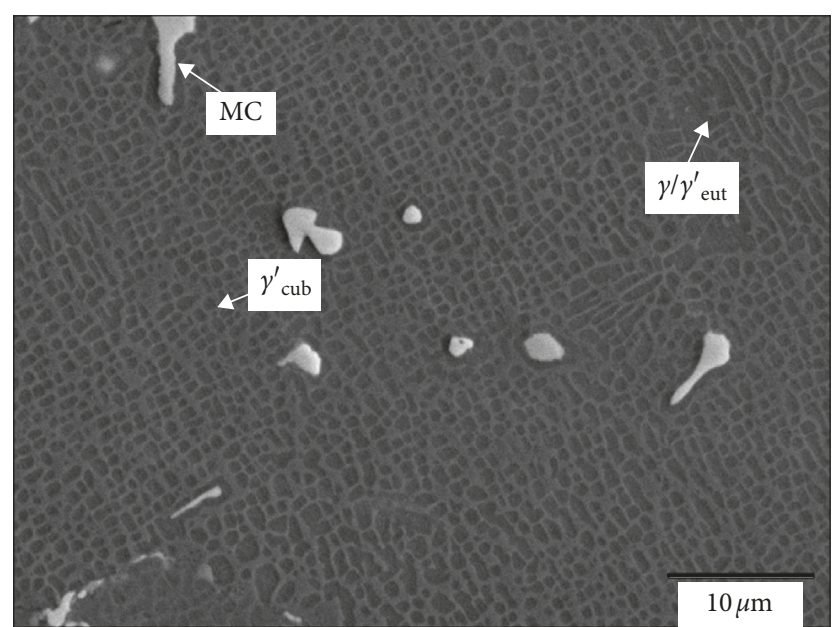

(a)

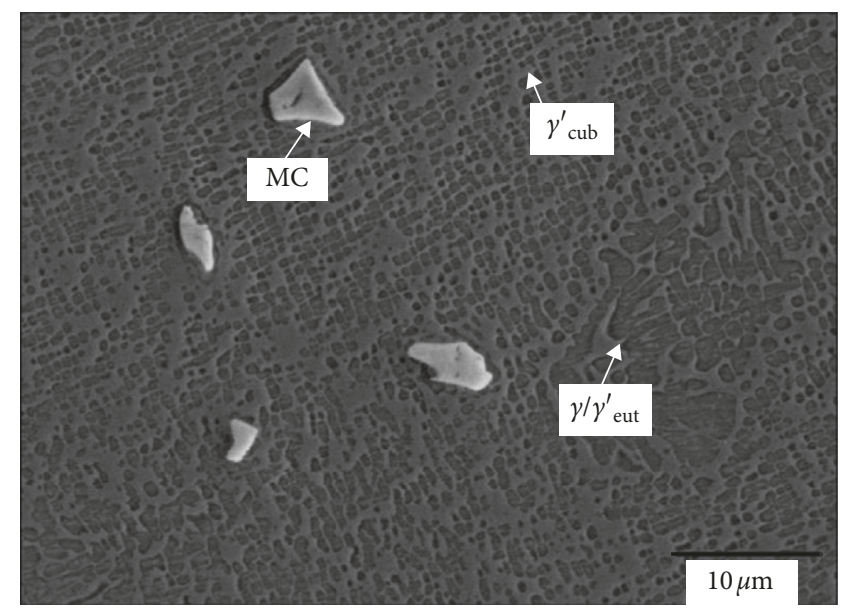

(b)

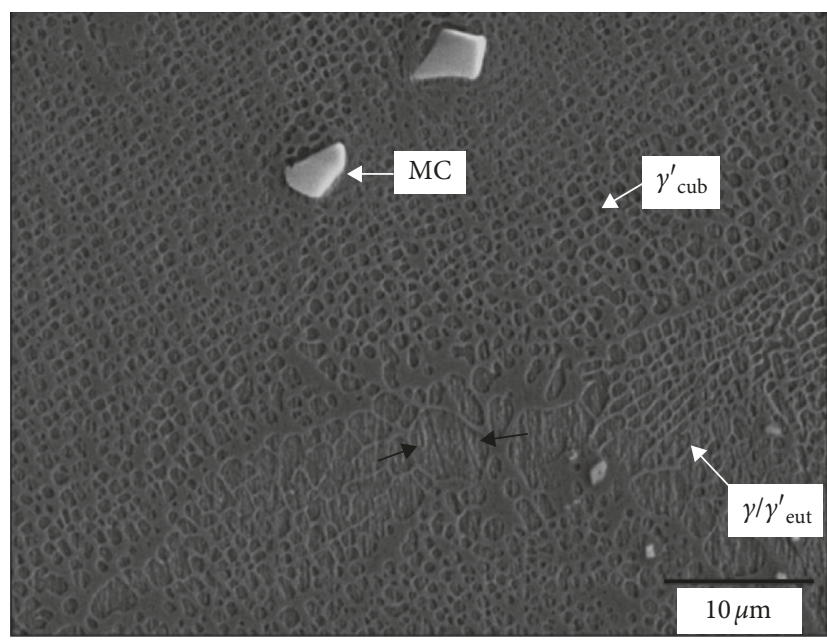

(c)

FIgURE 9: SEM micrographs of IN-792 superalloy for (a) MT: $1147 \mathrm{~K}\left(874^{\circ} \mathrm{C}\right)$; (b) HT: $1211 \mathrm{~K}\left(938^{\circ} \mathrm{C}\right)$; (c) LT: $1091 \mathrm{~K}\left(818^{\circ} \mathrm{C}\right)$.

phase region is observed for 3.2 wt.\% of aluminum. The eutectic constituent of the $\gamma$ and $\gamma^{\prime}$ phases is still present, and it seems that this treatment caused no change in them. This is in good agreement with the formation temperature, $1504 \mathrm{~K}$ $\left(1231^{\circ} \mathrm{C}\right)$, of $\gamma / \gamma^{\prime}$ eutectic reported in literature [33]. The following aging at $1353 \mathrm{~K}\left(1080^{\circ} \mathrm{C}\right)$ for $4 \mathrm{~h}$ and aging at $1118 \mathrm{~K}\left(845^{\circ} \mathrm{C}\right)$ for $24 \mathrm{~h}$ have no effect on $\gamma / \gamma^{\prime}$ eutectic (Figures 12(d)-12(f)). MC carbides seem to be unaffected for both treatments (Figures 12(a)-12(f)). However, $\mathrm{M}_{23} \mathrm{C}_{6}$ carbides were dissolved apparently, which is consistent with the phase diagram obtained by Thermo-Calc that shows no $\mathrm{M}_{23} \mathrm{C}_{6}$ carbide presence at $1393 \mathrm{~K}\left(1120^{\circ} \mathrm{C}\right)$, solution treating temperature.

Furthermore, the XRD pattern, as shown in Figure 13(a), for the specimen with the first heat treatment shows only the presence of $\gamma$ and $\gamma^{\prime}$ phases. The hardness for this section of the in-service operation specimen was $453 \mathrm{VHN}$ in comparison to $452 \mathrm{VHN}$ for the specimen with first treatment. That is, there is almost no change in hardness. In contrast, the specimen with the second treatment, complete heat treatment, shows the presence of very small spherical $\gamma^{\prime}$ precipitates, $<100 \mathrm{~nm}$, located among the original $\gamma^{\prime}$ precipitates as a result of aging at $1118 \mathrm{~K}\left(845^{\circ} \mathrm{C}\right)$. In addition, the XRD for this specimen, as shown in Figure 13(b), again indicates only the presence of the $\gamma$ and $\gamma^{\prime}$ phases.

In a previous experimental study [36], it was analyzed the as-cast microstructure of an IN-792 superalloy, obtained by conventional cast process. They identified $\gamma$ matrix phase, $\gamma^{\prime}$ phase, $\gamma / \gamma^{\prime}$ eutectic, and carbides. Then, after a heat treatment of solution treated at $1393 \mathrm{~K}\left(1120^{\circ} \mathrm{C}\right)$, they concluded that the MC carbides and rose-shaped $\gamma / \gamma^{\prime}$ eutectic partly dissolves into $\gamma$ matrix phase and $\mathrm{M}_{23} \mathrm{C}_{6}$ carbide forms. In this study, $\mathrm{M}_{23} \mathrm{C}_{6}$ carbides were not observed after a heat treatment of solution treated at $1393 \mathrm{~K}\left(1120^{\circ} \mathrm{C}\right)$. It can be a consequence of the differences in chemical composition between the alloys studied. Then, after two-stage aging process with $4 \mathrm{~h}$ at $1353 \mathrm{~K}\left(1080^{\circ} \mathrm{C}\right)$ and $24 \mathrm{~h}$ at $1118 \mathrm{~K}$ $\left(845^{\circ} \mathrm{C}\right)$ in [36], they identified $\gamma^{\prime}$ phase arranged regularly and the reprecipitation of profuse fine $\gamma^{\prime}$ throughout $\gamma$ matrix channels. These results are in good agreement with the experimental results of this study.

The hardness for this complete heat treatment was 410 VHN, lower than the first treatment. This can be attributed 

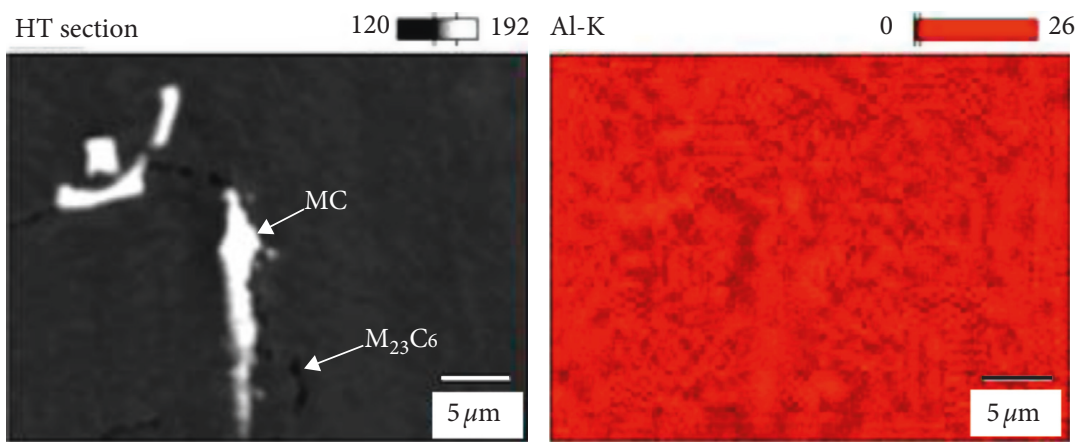

6 Ti-K
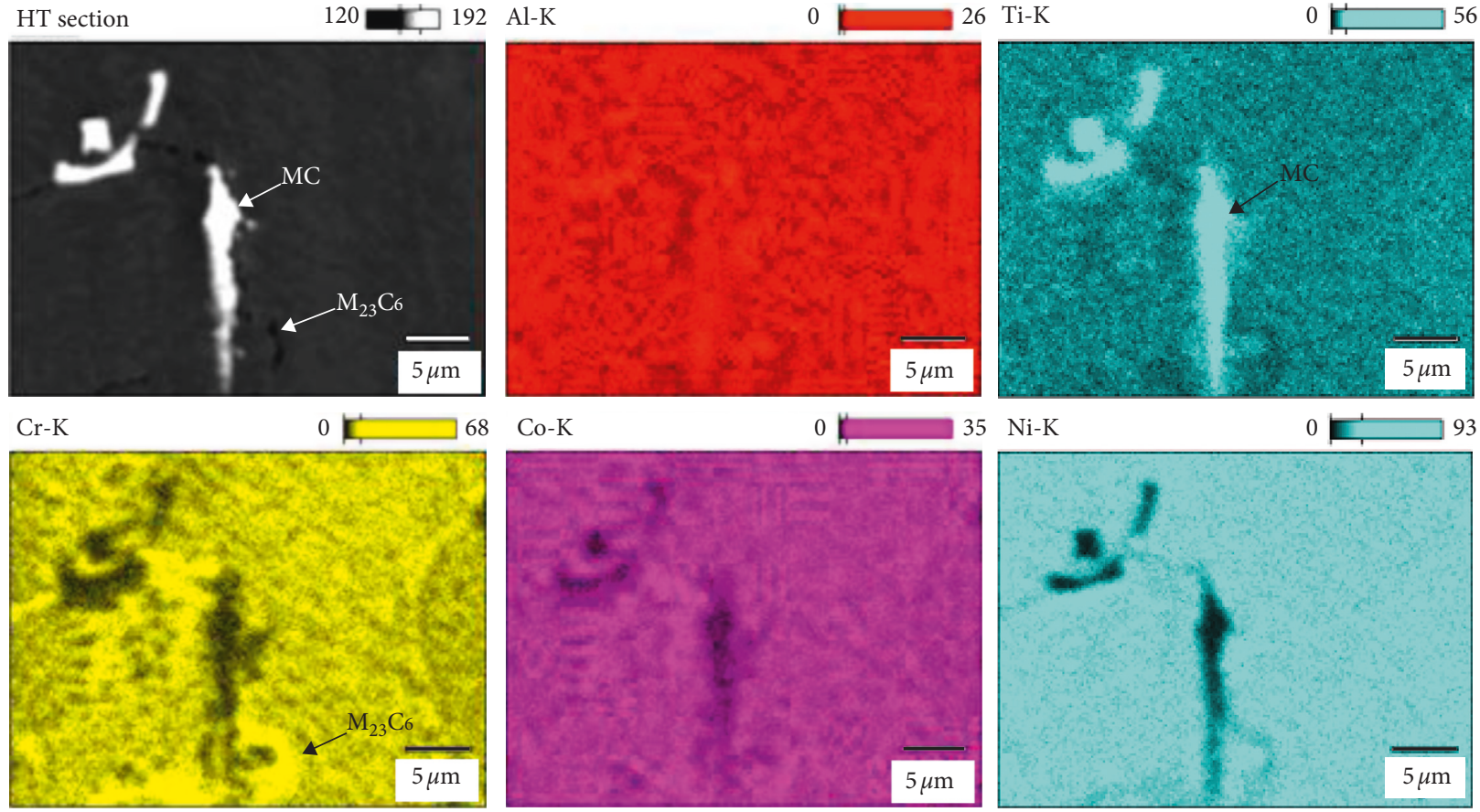

0

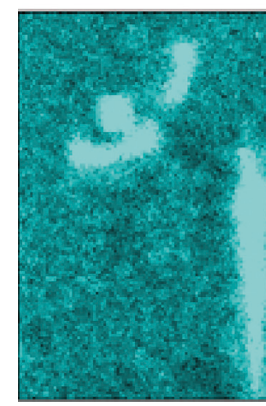

$0 \longdiv { 1 } 5 6$
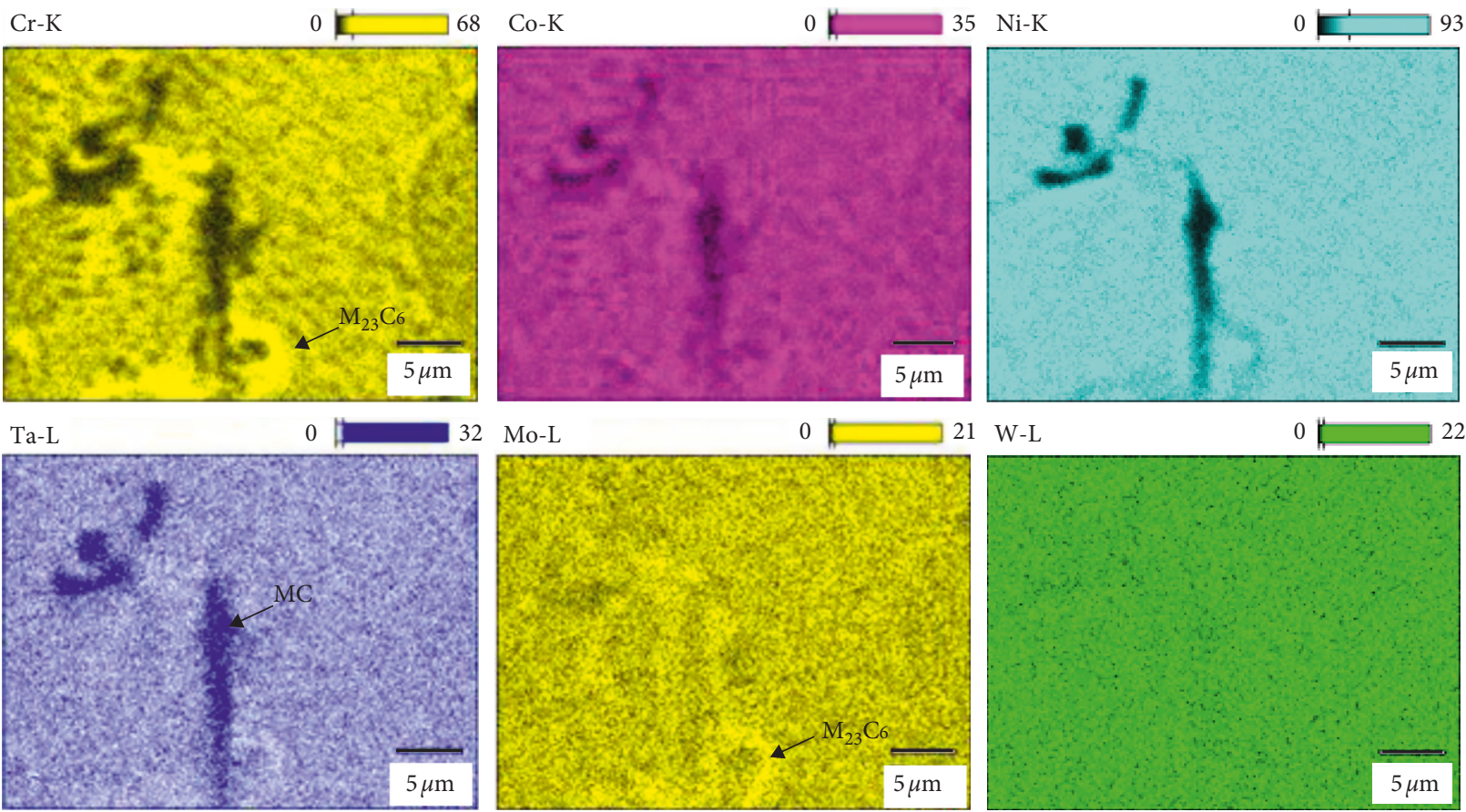

FIGURE 10: Element-imaging SEM analysis of IN-792 superalloy for HT section.

to the loss of solute in the $\gamma$ matrix phase because of the precipitation of small $\gamma^{\prime}$ precipitates and to the dissolution of $\mathrm{M}_{23} \mathrm{C}_{6}$ carbides in the IN-792 superalloy, after applying the reheat treatments.

The precipitation of small $\gamma^{\prime}$ particles are in good agreement with the TTP diagram of Figure 5 determined by TC-PRISMA. Like in [36], in this study was not observed cold crack formation at grain boundaries for a solution temperature of $1393 \mathrm{~K}\left(1120^{\circ} \mathrm{C}\right)$. Finally, for both heat treatments, the heating at $1393 \mathrm{~K}\left(1120^{\circ} \mathrm{C}\right)$ is not enoughly high for dissolving the $\gamma / \gamma^{\prime}$ eutectics and the carbides of the MC type in the microstructure of the IN-792 superalloy. On the other hand, the complete heat treatment promotes a distribution more regular and homogeneous of $\gamma^{\prime}$ precipitates, and their size and morphology become finer and cuboidal, respectively, because of the reprecipitation $\gamma^{\prime}$ particles throughout $\gamma$ matrix phase.

\section{Conclusions}

Experimental and numerical analysis of the microstructure evolution for the IN-792 superalloy, extracted from a gas turbine blade, was conducted, and the conclusions are as follows:

(a) The Thermo-Calc analysis based on the equilibrium and nonequilibrium diagrams permitted to explain the phase formation during the solidification of the superalloy. The MC carbides were first formed during the solidification, and then the eutectic constituent, composed of the $\gamma$ and $\gamma^{\prime}$ phases, was formed. These calculated results are in good agreement with the phases observed microscopically in the superalloy.

(b) The calculated time-temperature-precipitation diagram shows that if an isothermal aging is carried out in the IN-792 superalloy at temperatures between approximately $1198 \mathrm{~K}\left(925^{\circ} \mathrm{C}\right)$ and $1323 \mathrm{~K}\left(1050^{\circ} \mathrm{C}\right)$, the following precipitation reaction occurs: $\gamma \longrightarrow \gamma+\gamma^{\prime}$, and the growth kinetic of precipitation of the $\gamma^{\prime}$ phase is very fast. The precipitation sequence for aging at temperatures of about $873 \mathrm{~K}$ $\left(600^{\circ} \mathrm{C}\right)$ and $1173 \mathrm{~K}\left(900^{\circ} \mathrm{C}\right)$ is as follows: $\gamma \longrightarrow \gamma+$ $\gamma^{\prime} \longrightarrow \gamma+\mu \longrightarrow \gamma+\mathrm{M}_{23} \mathrm{C}_{6} \longrightarrow \gamma+\mathrm{Ni}_{3} \mathrm{Ti}$. All these precipitated phases are in agreement with those phases observed experimentally from the 


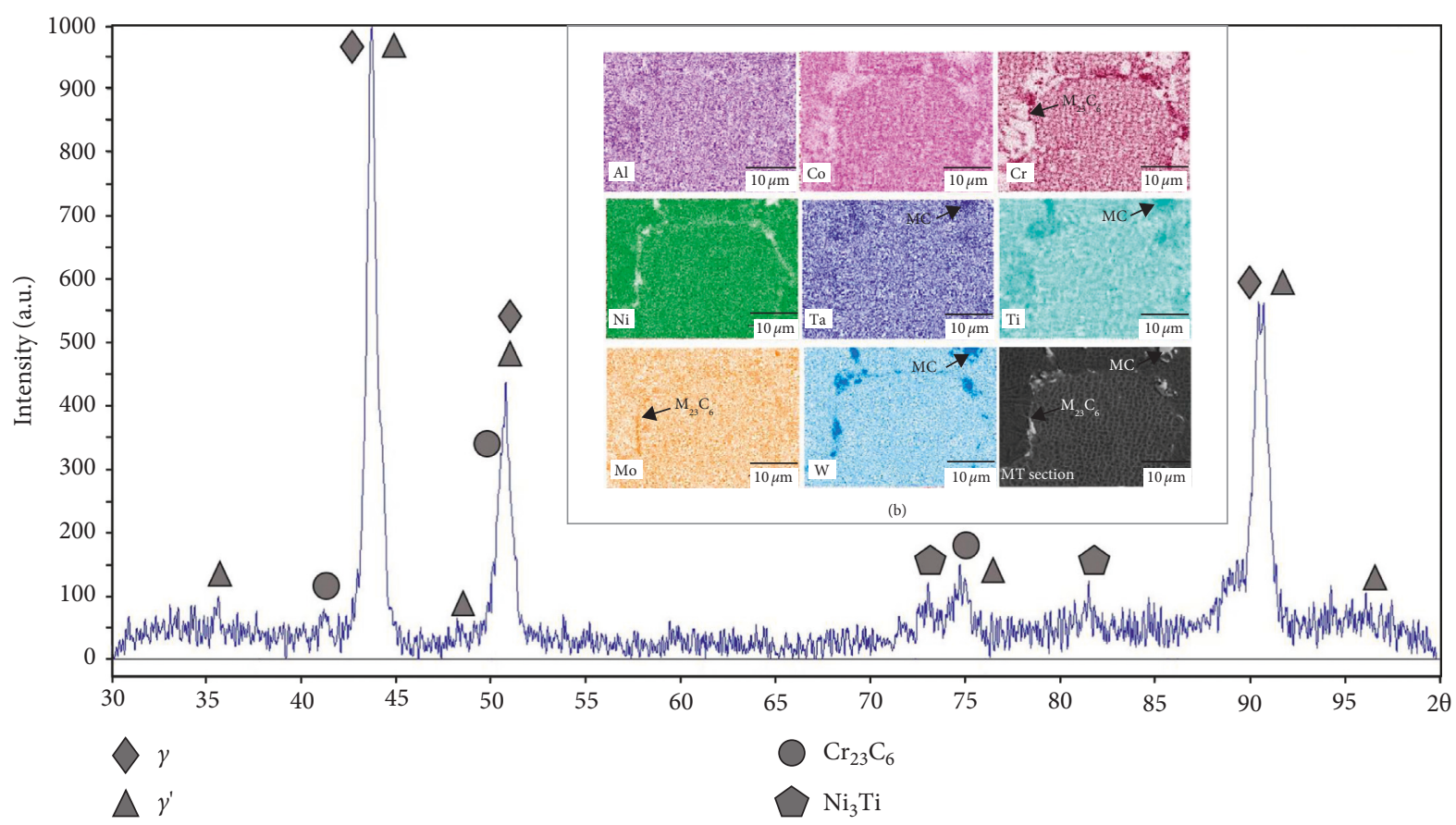

(a)

FIGURE 11: Characterization of the IN-792 superalloy. MT section by (a) XRD pattern and (b) element-imaging SEM analysis.

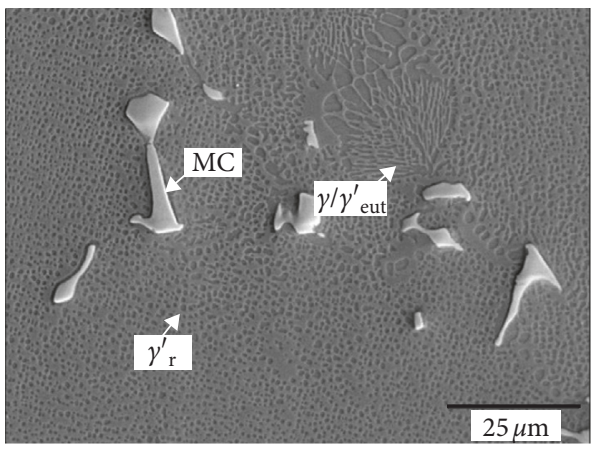

(a)

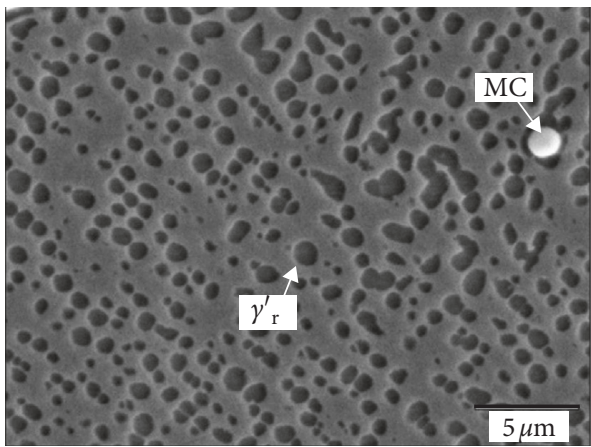

(c)

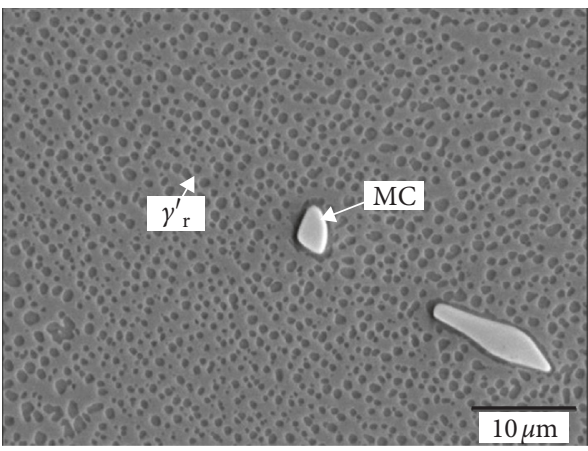

(b)

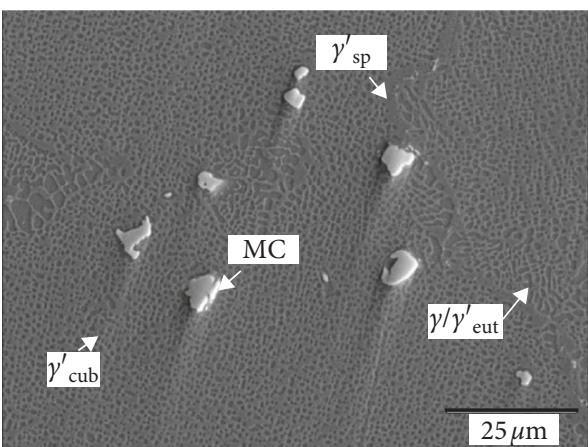

(d)

Figure 12: Continued. 


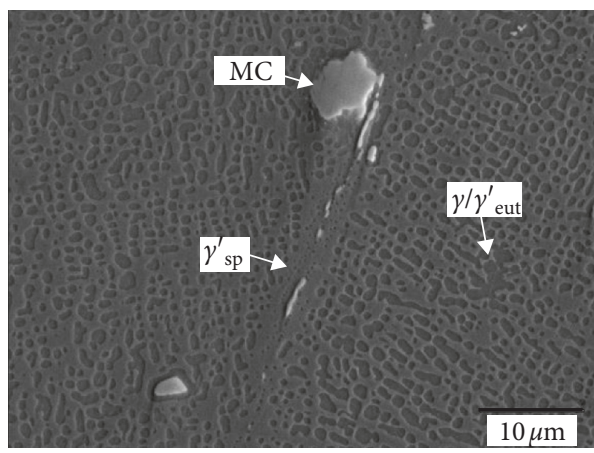

(e)

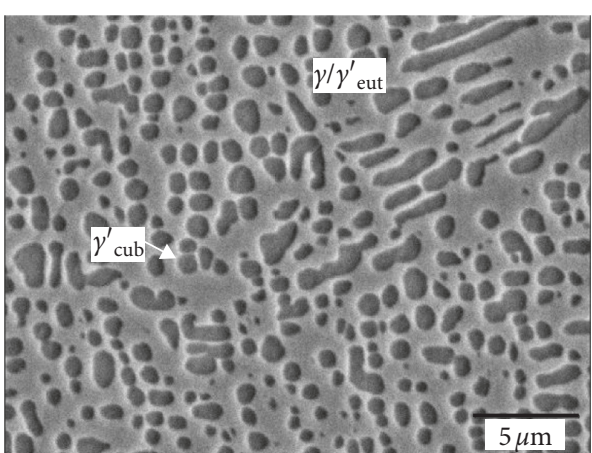

(f)

FIGURE 12: SEM micrographs of the reheat treatment blade for the conditions: $(a-c)$ solution treating and $(d-f)$ complete heat treatment.

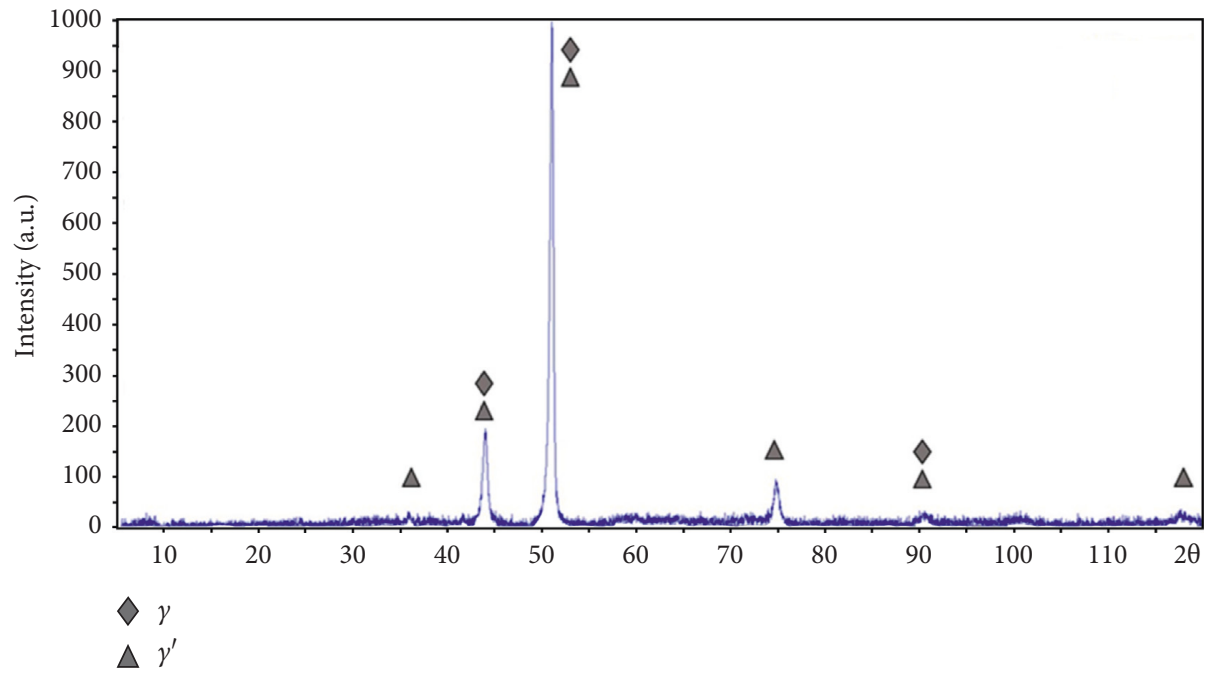

(a)

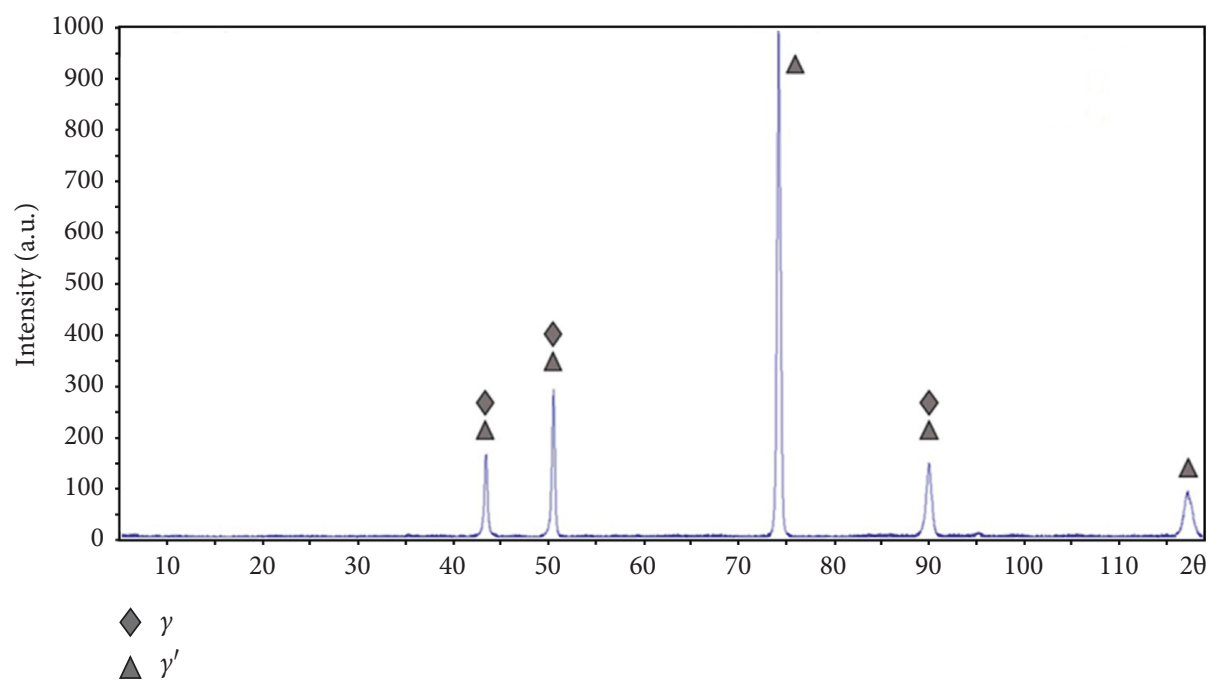

(b)

FIGURE 13: XRD patterns of the IN-792 superalloy with the following heat treatment conditions: (a) solution treating and (b) complete heat treatment. 
microstructural characterization of in-service operation blade.

(c) In the case of both conducted reheat treatments, no effect of dissolution was observed on the $\gamma / \gamma^{\prime}$ eutectic and $\mathrm{MC}$ carbides. The $\mathrm{M}_{23} \mathrm{C}_{6}$ carbides were dissolved, apparently. This is consistent with the phase diagram obtained by Thermo-Calc that shows no $\mathrm{M}_{23} \mathrm{C}_{6}$ carbide presence at the solution treating temperature, $1393 \mathrm{~K}\left(1120^{\circ} \mathrm{C}\right)$. For the condition of heating at $1393 \mathrm{~K}\left(1120^{\circ} \mathrm{C}\right)$ for $4 \mathrm{~h}$ and subsequently air cooling, it was observed partial dissolution of the $\gamma^{\prime}$ phase and the precipitation of the $\gamma^{\prime}$ phase with a morphology round instead of cuboidal. In the case of the complete heat treatment, the fine secondary $\gamma^{\prime}$ precipitates showed a more regular distribution and bimodal type. These results are consistent with the calculated TTP diagram.

(d) The difference in the hardness values for the sections' in-service operation can be attributed as a consequence of the $\gamma^{\prime}$ average size and due to the high volume fraction of $\mathrm{MC}$ and $\mathrm{M}_{23} \mathrm{C}_{6}$ carbides, considering their intra- and intergranular distribution in the $\gamma$ matrix phase. Nevertheless, it was not obtained an evident change in hardness for the specimen with the first treatment. In contrast, the specimen with a complete heat treatment showed hardness lower than the first treatment. This can be a consequence of the loss of solute in the $\gamma$ matrix phase due to the reprecipitation of small $\gamma^{\prime}$ particles and of the dissolution of $\mathrm{M}_{23} \mathrm{C}_{6}$ carbides in the IN-792 superalloy, after applying the reheat treatments.

(e) The $\eta$ phase was detected in the samples for the sections in-service operation, experimentally. In contrast, it was not identified in the samples reheattreated. Then, for this IN-792 superalloy, its presence is due to the prolonged exposure at high temperatures of the blades. Similarly, the $\mu$ phase was predicted to appear in the IN-792 superalloy by Thermo-Calc and TC-PRISMA software. Thus, it is expected that the coarse microconstituent with an irregular plate shape observed in the LT section of the blade, after in-service operation, corresponds to the $\mu$ phase. However, there is good agreement between the numerical and experimental results obtained.

\section{Data Availability}

The Thermo-Calc and TC-PRISMA data used to support the findings of this study were supplied by Thermo-Calc software under perpetual license and so cannot be made freely available. Also, the Thermo-Calc and TC-PRISMA data used are mentioned in references [26, 28, 30] within the article. Previously reported computational fluid dynamics (CFD) data were used to support this study and are available in reference [24], within the article. These prior studies were used to calculate the service temperatures inside the blade.

\section{Conflicts of Interest}

The authors declare that there are no conflicts of interest regarding the publication of this paper.

\section{Acknowledgments}

The authors wish to acknowledge the financial support from CONACYT and from TecNM (6554.18-P project).

\section{References}

[1] J. R. Davis, ASM Specialty Handbook: Heat-Resistant Materials, ASM International, Materials Park, OH, USA, 1st edition, 1997.

[2] R. C. Reed, The Superalloys Fundamentals and Applications, Cambridge University Press, New York, NY, USA, 1st edition, 2006.

[3] T. M. Pollock and S. Tin, "Nickel-based superalloys for advanced turbine engines: chemistry, microstructure, and properties," Journal of Propulsion and Power, vol. 22, pp. 361-374, 2006.

[4] B. Du, J. Yang, C. Cui, and X. Sun, "Effects of grain size on the high-cycle fatigue behavior of IN792 superalloy," Materials and Design, vol. 65, pp. 57-64, 2015.

[5] L. Yang, Q. X. Liu, Y. C. Zhou, W. G. Mao, and C. Lu, "Finite element simulation on thermal fatigue of a turbine blade with thermal barrier coatings," Journal of Materials Science \& Technology, vol. 30, no. 4, pp. 371-380, 2014.

[6] R. C. Ecob, R. A. Ricks, and A. J. Porter, "The measurement of precipitate/matrix lattice mismatch in nickel-base superalloys," Scripta Metallurgica, vol. 16, no. 9, pp. 1085-1090, 1982.

[7] A. Sato, J. J. Moverare, M. Hasselqvist, and R. C. Reed, "On the mechanical behavior of a new single-crystal superalloy for industrial gas turbine applications," Metallurgical and Materials Transactions A, vol. 43, no. 7, pp. 2302-2315, 2012.

[8] R. W. Kozar, A. Suzuki, W. W. Milligan, J. J. Schirra, M. F. Savage, and T. M. Pollock, "Strengthening mechanisms in polycrystalline multimodal nickel-base superalloys," Metallurgical and Materials Transactions A, vol. 40, no. 7, pp. 1588-1603, 2009.

[9] K. V. Dahl and J. Hald, "Identification of precipitates in an IN792 gas turbine blade after service exposure," Practical Metallography, vol. 50, no. 6, pp. 432-450, 2013.

[10] S. Gorgannejad, E. A. Estrada Rodas, and R. W. Neu, "Ageing kinetics of Ni-base superalloys," Materials at High Temperatures, vol. 33, no. 4-5, pp. 291-300, 2016.

[11] I. Lopez-Galilea, J. Koßmann, A. Kostka1 et al., "The thermal stability of topologically close-packed phases in the singlecrystal Ni-base superalloy ERBO/1," Journal of Materials Science, vol. 51, no. 5, pp. 2653-2664, 2016.

[12] P. Wangyao, N. Chuankrerkkul, S. Polsilapa, P. Sopon, and W. Homkrajai, "Gamma prime phase stability after long-term thermal exposure in cast nickel based superalloy, IN-738," Chiang Mai Journal of Science, vol. 36, pp. 312-319, 2009.

[13] J. Yang, Z. Qi, M. Ji, X. Sun, and Z. Hu, "Effects of different C contents on the microstructure, tensile properties and stressrupture properties of IN792 alloy," Materials Science and Engineering: $A$, vol. 528, no. 3, pp. 1534-1539, 2011.

[14] K. Zhao, Y. H. Ma, L. H. Lou, and Z. Q. Hu, " $\mu$ phase in a nickel base directionally solidified alloy,” Materials Transactions, vol. 46, no. 1, pp. 54-58, 2005. 
[15] A. S. Wilson, "Formation and effect of topologically closepacked phases in nickel-base superalloys," Materials Science and Technology, vol. 33, no. 9, pp. 1108-1118, 2017.

[16] Q. Chen, K. Wu, G. Sterner, and P. Mason, "Modeling precipitation kinetics during heat treatment with calphadbased tools," Journal of Materials Engineering and Performance, vol. 23, no. 12, pp. 4193-4196, 2014.

[17] O. Prat, J. García, D. Rojas, J. P. Sanhueza, and C. Camurri, "Study of nucleation, growth and coarsening of precipitates in a novel 9\%Cr heat resistant steel: experimental and modeling," Materials Chemistry and Physics, vol. 143, no. 12, pp. 754-764, 2014.

[18] M. G. Fahrmann and D. A. Metzler, "Simulation of $\gamma^{\prime}$ precipitation kinetics in a commercial Ni-base superalloy," JOM, vol. 68, no. 11, pp. 2786-2792, 2016.

[19] G. F. Vander Voort, G. M. Lucas, and E. P. Manilova, "Metallography and microstructures of heat-resistant alloys," in ASM Handbook: Metallography and Microstructures, vol. 9, pp. 820-859, ASM International, Materials Park, OH, USA, 2004.

[20] S. Somashekar, R. Prem Chand, K. M. Chandrashekar, and D. Sachin, "Design and structural analysis of turbine blades," International Journal for Research in Applied Science \& Engineering Technology (IJRASET), vol. 5, pp. 1572-1578, 2017.

[21] N. L. Sindhu and N. Chikkanna, "Design and analysis of gas turbine blade," International Journal for Research in Applied Science \& Engineering Technology (IJRASET), vol. 5, pp. 1097-1104, 2017.

[22] M. Tofighi Naeem, N. Rezamahdi, and S. A. Jazayeri, "Failure analysis of gas turbine blades," International Journal of Engineering Research \& Innovation, vol. 1, pp. 29-36, 2009.

[23] J. R. Davis, ASM Specialty Handbook: Nickel, Cobalt, and their Alloys, ASM International, Materials Park, OH, USA, 2000.

[24] Online World Academy of Science, "Engineering and technology (WASET)," September 2016, https://waset.org/ Publication/fatigue-life-consumption-for-turbine-blades-vanesaccelerated-by-erosion-contour-modification/10962.

[25] Maintenance Manual MFT4-CID/LF, vol. 1-2.

[26] Online Thermo-Calc, "Thermodynamic equilibrium calculations," November 2016, http://www.Thermo-Calc.com/index. html.

[27] D. A. Porter and K. E. Easterling, Phase Transformations in Metals and Alloys, Chapman and Hall, London, UK, 2nd edition, 1992.

[28] Online TC-PRISMA, "Thermodynamic and diffusion calculations," December 2016, http://www.Thermo-Calc.com/ index.html.

[29] G. Kostorz, Phase Transformations in Materials, Wiley-VCH, Weinheim, Germany, 2001.

[30] Online database Thermo-Calc, "Thermodynamic equilibrium calculations," November 2016, http://www.thermocalc.com/ media/23648/tcni8.pdf and http://www.thermocalc.com/media/ 23658/mobni8.pdf.

[31] E. Poursaeidi, A. Kavandi, K. Vaezi, M. R. Kalbasi, and M. R. Mohammadi Arhani, "Fatigue crack growth prediction in a gas turbine casing," Engineering Failure Analysis, vol. 44, pp. 371-381, 2014.

[32] B. Deepanraj, P. Lawrence, and G. Sankaranarayanan, "Theoretical analysis of gas turbine blade by finite element method," Scientific World, vol. 9, no. 9, pp. 29-33, 2011.

[33] S. Zlá, J. Dobrovská, B. Smetana, M. Žaludová, V. Vodárek, and K. Konečná, "Thermophysical and structural study of IN 792-5a nickel based speralloy,” Metalurgija, vol. 51, pp. 83-66, 2012.
[34] Y. Xu, L. Zhang, J. Li et al., "Relationship between Ti/Al ratio and stress-rupture properties in nickel-based superalloy," Materials Science and Engineering: A, vol. 544, pp. 48-53, 2012.

[35] D. Locq, L. Nazé, J.-M. Franchet et al., "Metallurgical optimisation of PM superalloy N19," in Proceedings of Eurosuperalloys 2014, p. 6, Giens, France, May 2014.

[36] J. Yang, Q. Zheng, H. Zhang, X. Sun, H. Guan, and Z. Hu, "Effects of heat treatments on the microstructure of IN792 alloy," Materials Science and Engineering: A, vol. 527, no. 4-5, pp. 1016-1021, 2010. 


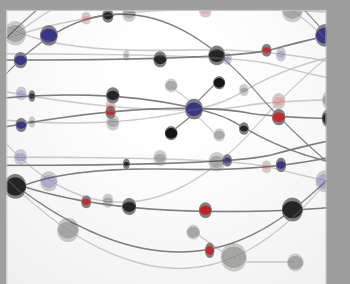

The Scientific World Journal
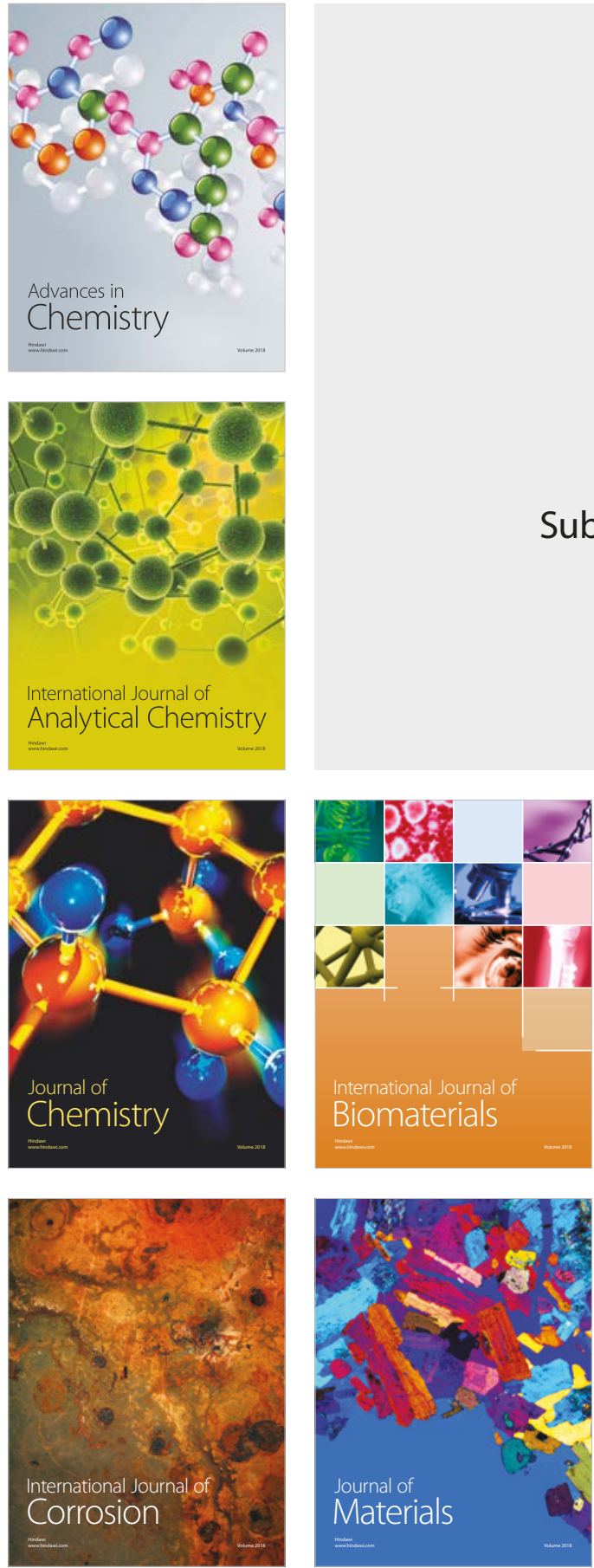

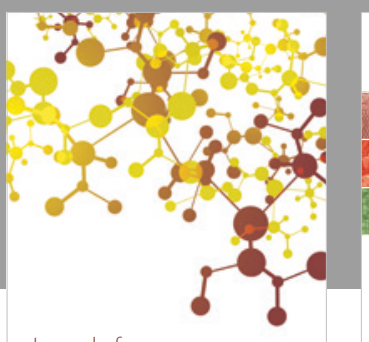

Journal of

Applied Chemistry
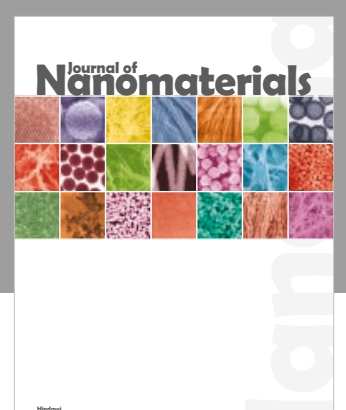

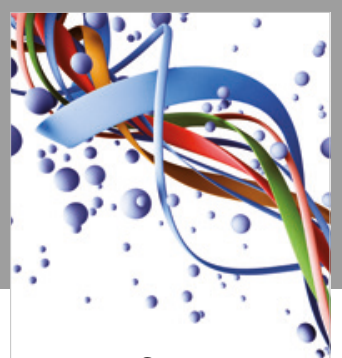

Scientifica

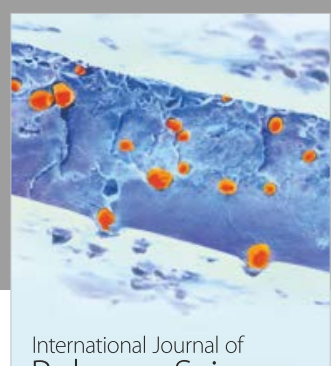

Polymer Science

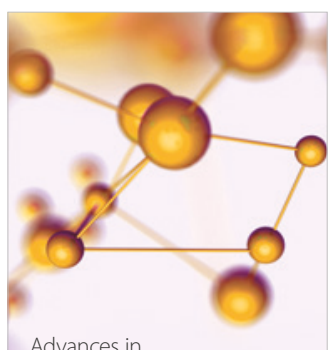

Physical Chemistry
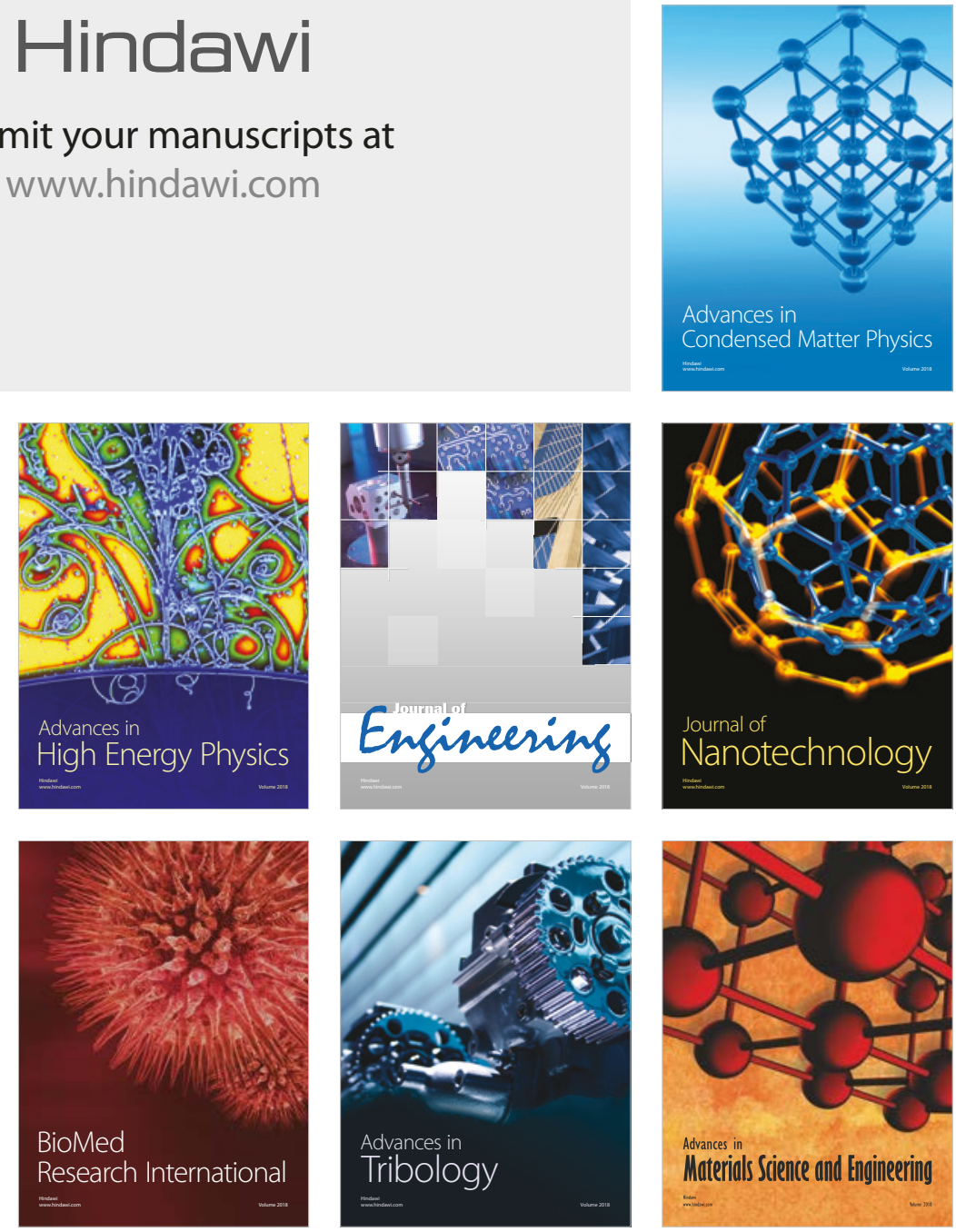